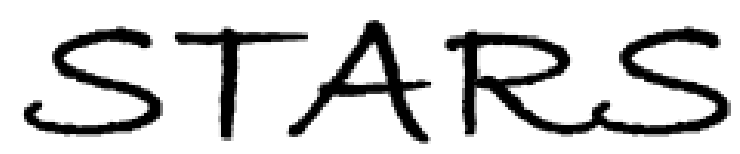

University of Central Florida

STARS

2013

\title{
Investigation On Electrical Properties Of Rf Sputtered Deposited Bcn Thin Films
}

Adithya Prakash

University of Central Florida

Part of the Electrical and Electronics Commons

Find similar works at: https://stars.library.ucf.edu/etd

University of Central Florida Libraries http://library.ucf.edu

This Masters Thesis (Open Access) is brought to you for free and open access by STARS. It has been accepted for inclusion in Electronic Theses and Dissertations, 2004-2019 by an authorized administrator of STARS. For more information, please contact STARS@ucf.edu.

\section{STARS Citation}

Prakash, Adithya, "Investigation On Electrical Properties Of Rf Sputtered Deposited Bcn Thin Films" (2013). Electronic Theses and Dissertations, 2004-2019. 2677.

https://stars.library.ucf.edu/etd/2677

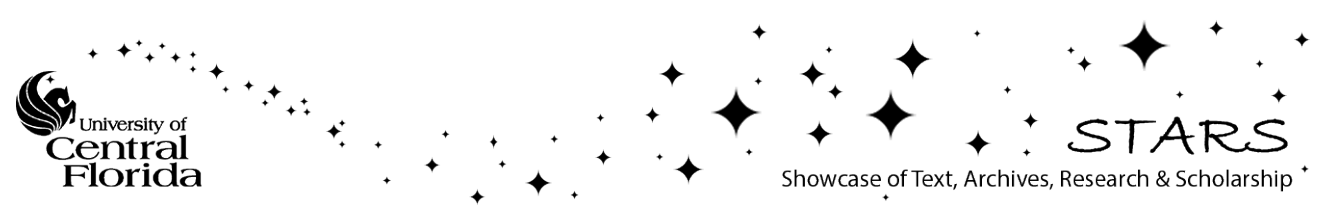




\section{INVESTIGATION ON ELECTRICAL PROPERTIES OF RF SPUTTERED DEPOSITED BCN}

THIN FILMS

by

ADITHYA PRAKASH
B.E. Visvesvaraya Technological University, 2011

A thesis submitted in partial fulfillment of the requirements for the degree of Master of Science

in the Department of Electrical Engineering and Computer Science in the College of Engineering and Computer Science at the University of Central Florida Orlando, Florida

Summer Term

2013 
(C) 2013 Adithya Prakash 


\begin{abstract}
The ever increasing advancements in semiconductor technology and continuous scaling of CMOS devices mandate the need for new dielectric materials with low-k values. The interconnect delay can be reduced not only by the resistance of the conductor but also by decreasing the capacitance of dielectric layer. Also cross-talk is a major issue faced by semiconductor industry due to high value of $\mathrm{k}$ of the inter-dielectric layer (IDL) in a multilevel wiring scheme in Si ultra large scale integrated circuit (ULSI) devices. In order to reduce the time delay, it is necessary to introduce a wiring metal with low resistivity and a high quality insulating film with a low dielectric constant which leads to a reduction of the wiring capacitance.
\end{abstract}

Boron carbon nitride $(\mathrm{BCN})$ films are prepared by reactive magnetron sputtering from a $\mathrm{B}_{4} \mathrm{C}$ target and deposited to make metal-insulator-metal (MIM) sandwich structures using aluminum as the top and bottom electrodes. BCN films are deposited at various $\mathrm{N}_{2} / \mathrm{Ar}$ gas flow ratios, substrate temperatures and process pressures. The electrical characterization of the MIM devices includes capacitance vs. voltage $(\mathrm{C}-\mathrm{V})$, current vs voltage, and breakdown voltage characteristics. The above characterizations are performed as a function of deposition parameters. 
To my grandfather late Mr. H Hanumanthaiah and my parents 


\section{ACKNOWLEDGMENTS}

I would like to thank my advisor, Dr. Kalpathy B Sundaram, for his continuous commitment to help and support me through my graduate career. His advice, technical and otherwise, has been valuable to my experience as a graduate student and as a person. I would also like to thank my committee members, Dr. Jiann S Yuan and Dr. Mingjie Lin, for their support throughout my years at UCF.

My heartfelt gratitude goes out to all of my colleagues at the lab - Giji Skaria, Ritika Oswal. Giji was very much instrumental in helping me to perform Vacuum Evaporation experiments and some basic electrical debugging.

I would like to thank my father Mr. H Prakash and my mother Mrs. Asha Prakash for their constant motivation and for instilling confidence in me at every step. Also I would like to thank my sister Ms. Ananya Prakash for her love and support. And last but not the least I would like to thank my grandparents and all my relatives and friends who stood by my side during ups and downs of my academic life here. 


\section{TABLE OF CONTENTS}

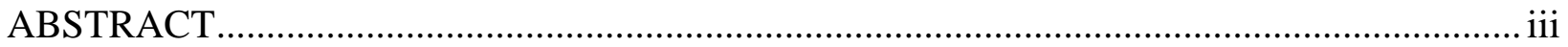

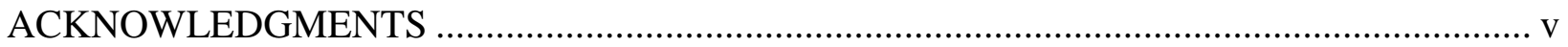

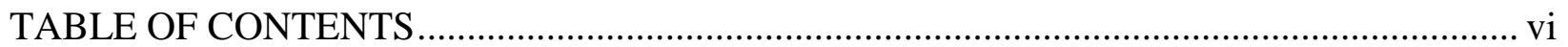

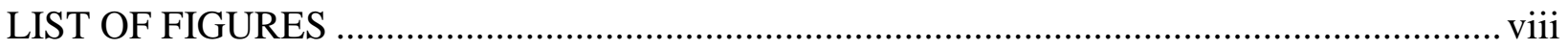

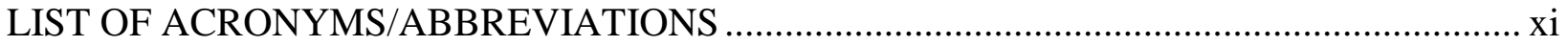

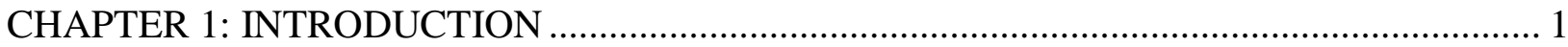

1.1: Inter Dielectric Layers (IDL) ............................................................................. 1

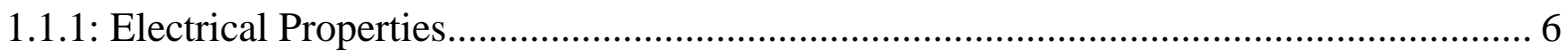

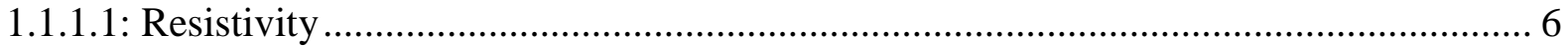

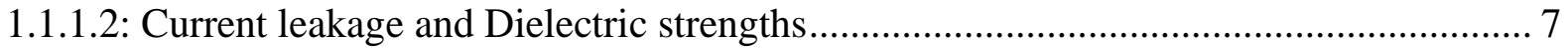

1.1.1.3: Polarization and charges in the dielectric ........................................................ 10

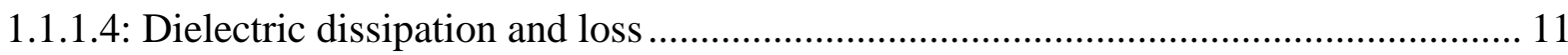

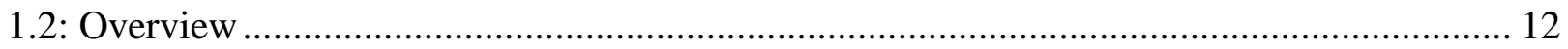

CHAPTER 2: LITERATURE REVIEW ....................................................................... 15

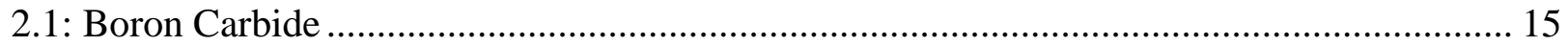

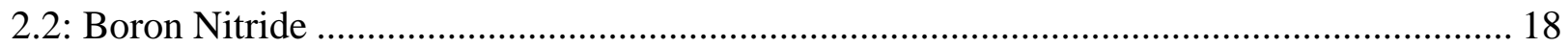

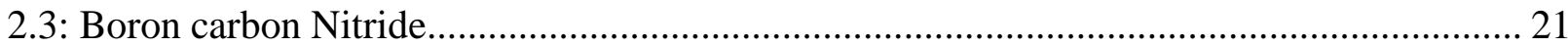

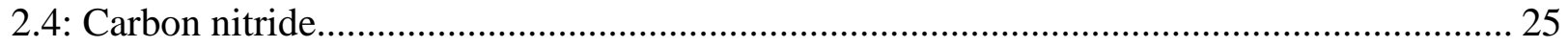




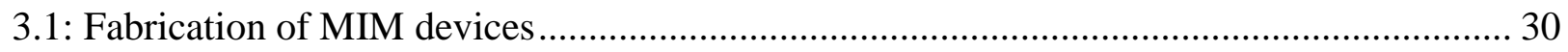

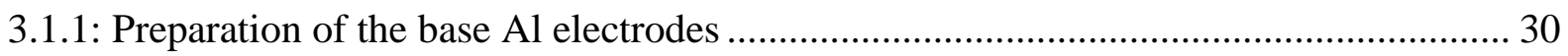

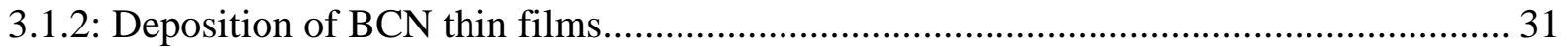

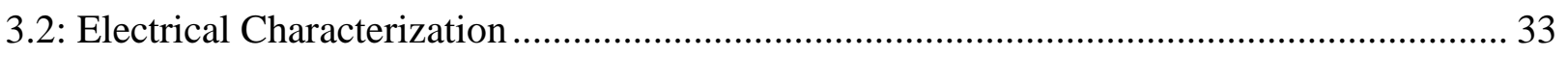

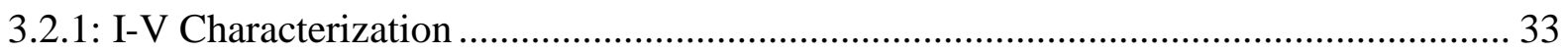

3.2.2: Dielectric constant measurement............................................................................. 34

3.2.3: Thickness measurement ........................................................................................... 35

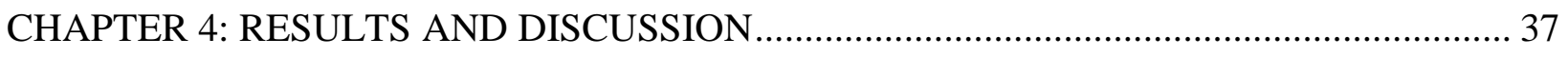

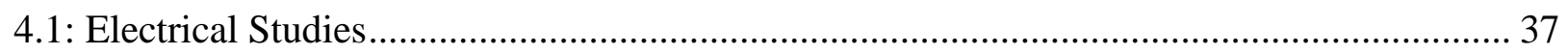

4.1.1: Dielectric constant v/s deposition temperatures ........................................................ 37

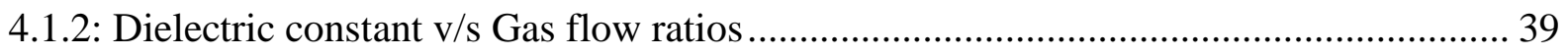

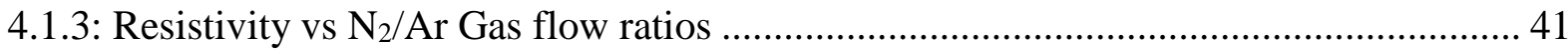

4.1.4: Resistivity vs Deposition temperature ...................................................................... 42

4.1.5: Breakdown Voltage vs $\mathrm{N}_{2} /$ Ar gas flow ratio ............................................................ 44

4.1.6: Breakdown Voltage vs Temperature ……………….................................................. 46

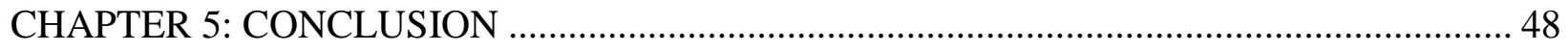

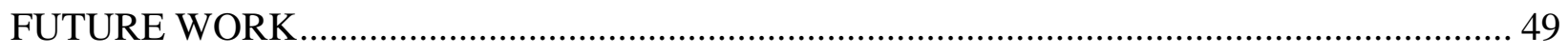

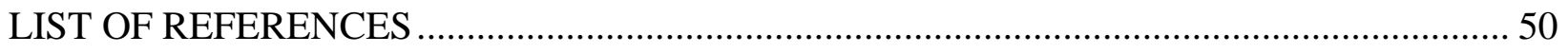




\section{LIST OF FIGURES}

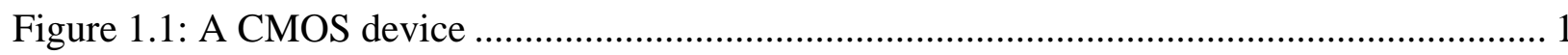

Figure 1.2: A typical interconnect element. LG and LL refer to the line-to-line and line-to-ground

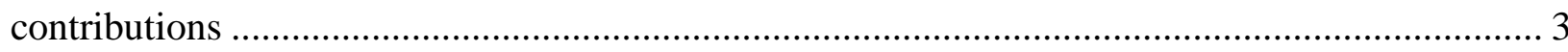

Figure 1.3: Relationship between the dielectric constant and mechanical strength, as represented by modulus of a representative ILD material. ................................................................... 5

Figure 1.4: Schematic representation of current density through a dielectric as a function of the

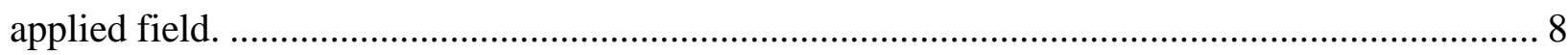

Figure 1.5: A log-log plot of the dielectric breakdown field (or field strengths), as a function of

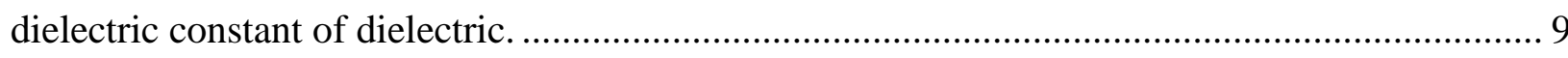

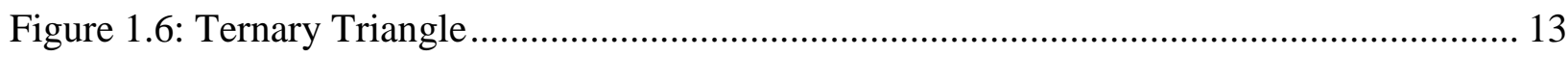

Figure 2.1: Icosahedron shape of unit cell of boron carbide. [10] ............................................... 16

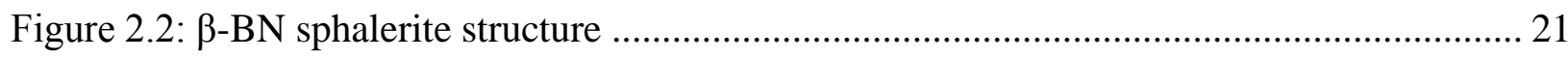

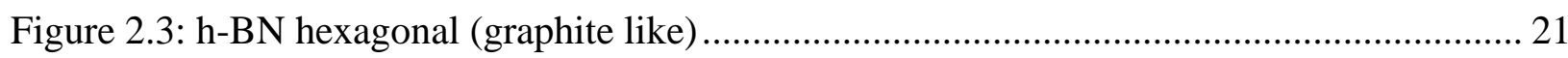

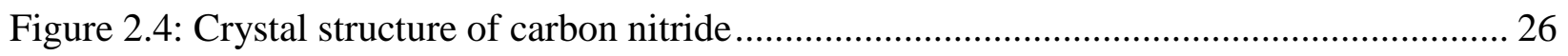

Figure 3.1: Sputtering Process Cartoon ............................................................................... 29

Figure 3.2: MIM structures (Al-BCN-Al) on a glass substrate ……………………................... 30

Figure 3.3: HP 4145B semiconductor parameter analyzer ...................................................... 34

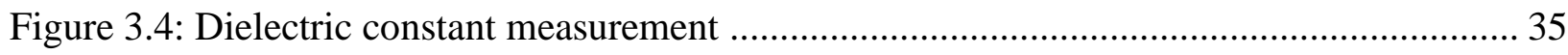

Figure 3.5: Veeco Dektak 150 profilometer …………….......................................................... 36

Figure 4.1: Effect of Temperature on Dielectric constant for 2 mtorr pressure ………………..... 38

Figure 4.2: Effect of Temperature on Dielectric constant for 5mtorr pressure. ………............... 39 
Figure 4.3: Effect of $\mathrm{N}_{2} / \mathrm{Ar}$ flow ratio on Dielectric constant at 2 mtorr pressure ..................... 40

Figure 4.4: Effect of $\mathrm{N}_{2}$ /Ar gas flow ratio on Dielectric constant at 5mtorr pressure ................ 40

Figure 4.5: Effect of N2/Ar gas flow ratio on Resistivity for 2mtorr pressure ........................ 41

Figure 4.6: Effect of $\mathrm{N}_{2} / \mathrm{Ar}$ gas flow ratio on Resistivity for 5mtorr pressure ......................... 42

Figure 4.7: Effect of deposition temperature on Resistivity for 5mtorr pressure ...................... 43

Figure 4.8: Effect of deposition temperature on Resistivity for 2 mtorr pressure ...................... 43

Figure 4.9: Effect of $\mathrm{N}_{2} / \mathrm{Ar}$ gas flow ratio on Breakdown voltage at 2mtorr pressure ................ 45

Figure 4.10: Effect of $\mathrm{N}_{2}$ /Ar gas flow ratio on Breakdown voltage at 5mtorr pressure ............. 45

Figure 4.11: Effect of Temperature on Breakdown voltage at 2mtorr pressure ....................... 47

Figure 4.12: Effect of Temperature on Breakdown voltage at 5mtorr pressure ........................ 47 


\section{LIST OF TABLES}

Table 1.1: Defining ILD characteristics......................................................................... 4

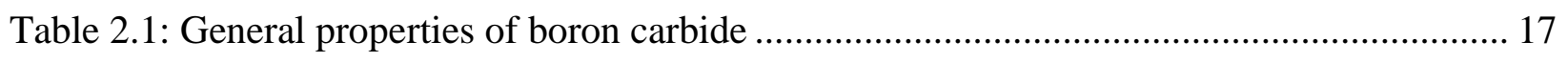

Table 2.2: Comparison of various properties of BN with those of other semiconductors ........... 20 


\section{LIST OF ACRONYMS/ABBREVIATIONS}

ARC

$\mathrm{BC}$

$\mathrm{BCN}$

BN

CMOS

CMP

CVD

IDL

$D C$

$E_{g}$
Anti-reflection coatings

Boron Carbide

Boron Carbon Nitride

Boron Nitride

Complementary Metal Oxide Semiconductor

Chemical Mechanical Polishing

Chemical Vapor Deposition

Inter Dielectric Layer

Direct Current

Band gap 


\section{CHAPTER 1: INTRODUCTION}

The horizontal and vertical conducting segments of transistors and other active parts of the semiconductor are connected by metallic lines. That serve as the gate metallization, contacts and metal interconnects that may consist of an adhesion promoter/diffusion barrier under and over the main current carrier metal as shown in the figure 1.1 and some processors contain nearly 10 levels of metallizations[1].

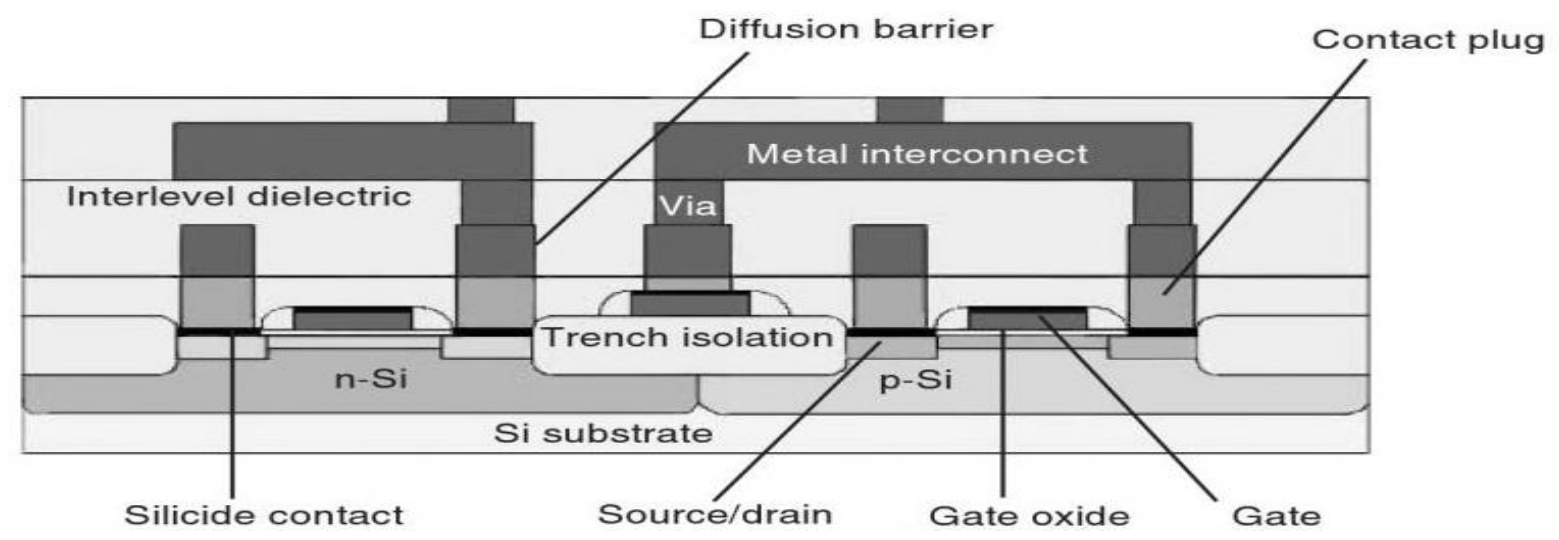

Figure 1.1: A CMOS device

\section{1: Inter Dielectric Layers (IDL)}

These are divided into three groups

(i) The active dielectric layers

(ii) Layers only for Device processing.

(iii) Insulating layers

The first group is used for storage of charges and other kind of active operation. Examples are gate oxide and dielectric capacitor in memory devices. The second group 
comprises of films which are used for device processing like (a) anti-reflection coatings (ARC) in lithography step; (b) etch stop layers and for chemical mechanical polishing (CMP) and (c) as masks.

The third group is used as insulation in microelectronic devices. The isolation between metal lines of same level is called inter-metal dielectric, and that between two metal levels is called inter level dielectric. Both are called interlayer dielectrics (ILDs). The effective speed of the devices is also due to the speed of signal propagation to and from the device through the metal interconnects. These are capacitvely coupled to the insulating dielectrics surrounding them, ILDs, leading to RC time delay.

An interconnects equivalent model is given in figure 1.2, where ' $\mathrm{P}$ ' is line pitch, ' $\mathrm{W}$ ' the line width, ' $\mathrm{S}$ ' the line spacing, ' $\mathrm{T}$ ' the line thickness, and the ILD line thickness above and below is equal. The RC delay is given by:

$\mathrm{RC}=2 \rho \kappa \epsilon_{0}\left[\left(4 \mathrm{~L}^{2} / \mathrm{P}^{2}\right)+\left(\mathrm{L}^{2} / \mathrm{T}^{2}\right)\right]$

Where $\rho$ is the metal resistivity, $\epsilon_{0}$ the vacuum permittivity, $\kappa$ the relative dielectric constant of the ILD, and L is the line length. For devices smaller than $0.25 \mu \mathrm{m}$, the RC time delay controls the overall on-chip cycle time. [2] 


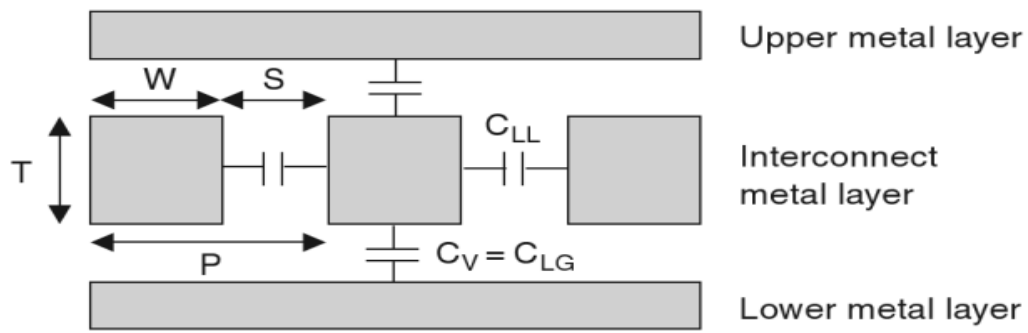

Figure 1.2: A typical interconnect element. LG and LL refer to the line-to-line and line-to-ground contributions. [2]

The power dissipation is also caused by parasitic capacitance as given by the following equation $P=(1 / 2) f_{d} C V^{2} f$

Where $\mathrm{C}$ is the total on-capacitance, $\mathrm{V}$ the supply voltage, $\mathrm{f}$ the operational frequency, and $f_{d}$ the fraction of gates that switch during a clock period. Thus by reducing $\kappa$, the value of 'C' will also be reduced making circuits faster, hence also more portable.

In this work the electrical properties of proposed ILD material is investigated. These all relate to electrical conduction through the dielectric and polarization that lead to interaction with electrons, as a result of applied field on the conductor in contact with dielectric. Some desired electrical properties in an ILD are high electrical bulk and surface resistivity, extremely low leakage, high electric field strength, low leakage, low charge trapping, dielectric constant, low dissipation and high reliability. The table below specifies all the electrical properties desired in a dielectric material of constant lower than 3. 
Table 1.1: Defining ILD characteristics

\begin{tabular}{|l|l|}
\hline Dielectric constant at $1 \mathrm{MHz}$ & $1.5-3$ \\
\hline Dissipation factor & $<0.005$ \\
\hline Anisotropy & Undesirable \\
\hline Breakdown strength & $\geq 1 \mathrm{MV} / \mathrm{cm}$ \\
\hline Bulk resistivity & $\geq 10^{15} \Omega \mathrm{cm}$ \\
\hline Surface resistivity & $\geq 10^{15} \Omega \mathrm{cm}$ \\
\hline
\end{tabular}

The list of the requirements of the low- $\kappa$ material is as given below;

1) Dielectric constant $<3.0$

2) Chemical compatibility with $\mathrm{Si}$

3) Highly insulating

4) Good thermal stability (up to $400^{\circ} \mathrm{C}$ )

5) High resistance to environmental degradation

6) Low hydrogen/moisture content

7) Compatibility with planarization, lithographic and etching processes

8) Low diffusivity for metallic impurities

9) High breakdown voltage

10) Low dissipation factor

11) Compositional uniformity

12) Low void/crack/defect density

13) Low compressive stress

14) Conformal deposition

15) Good adhesion 
16) Low deposition temperature

17) Thickness uniformity over large areas

18) Low particle density

19) High elastic modulus

20) Low shrinkage

21) Low thermal expansion

However, the main technology limiter was not the ability to develop low- $\kappa$ ILD materials but rather two fundamentally difficult problems associated with this category of materials. Firstly, is the inherent weak mechanical strength of low- $\kappa$ ILD which seriously limits the ability to package chips made with such ILDs. Moreover, the lower the dielectric constant, the weaker the ILD gets as shown in Fig 1.3. The second problem is the degradation of the dielectric constant of the low- $\kappa$ materials during processing. Typical processing steps used in the CMOS technology includes photo resist removal, dry and wet etch and metal cleans. All these steps extract carbon from the materials and render them to a higher dielectric constant.

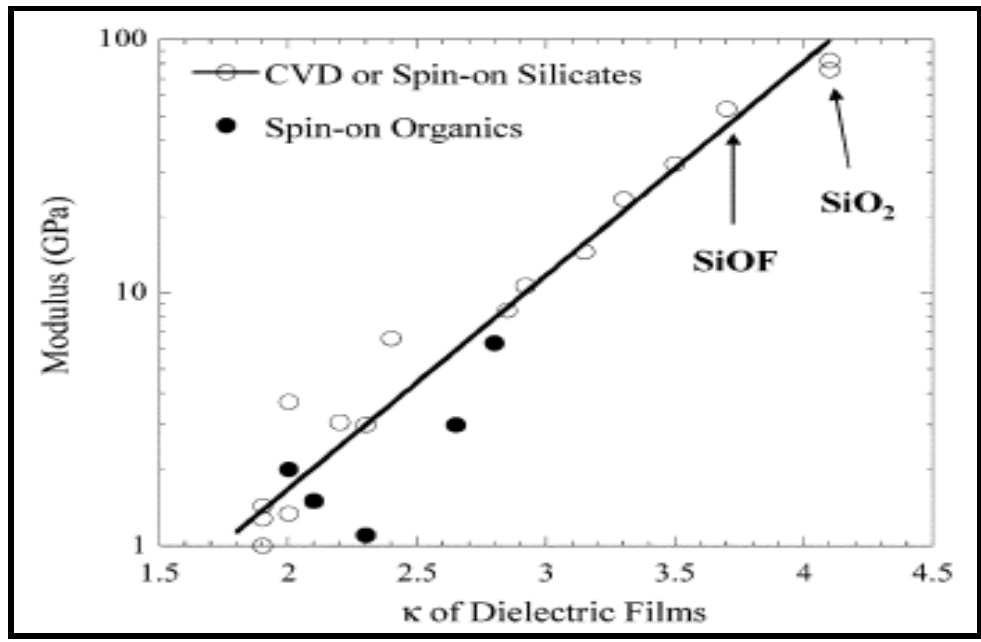

Figure 1.3: Relationship between the dielectric constant and mechanical strength, as represented by modulus of a representative ILD material. 
While the existence of a low dielectric constant is a critical requirement for any new low $\kappa$ dielectric material, it is far being the only requirement. It is equally important that the new material be chemically stable and compatible with Si microelectronics processing. As this work deals with the electrical properties of the BCN thin films. The desired electrical properties of an ideal dielectric material are discussed in the following section.

\subsection{1: Electrical Properties}

The need of good ILD material is in terms of high electrical bulk and surface resistivity, extremely low charge trapping, dielectric constant and its anisotropy, low dissipation and high reliability. Some of the desired ILD characteristics are dielectric constant at $1 \mathrm{MHz}$ may be from $1.5-3$, dissipation factor could be less than 0.005 , undesirable anisotropy, Breakdown strength should be greater than $1 \mathrm{MV} / \mathrm{Cm}$ and the surface resistivity should be greater than $10^{15} \Omega \mathrm{cm}$.

\subsubsection{1: Resistivity}

The resistivity determines the voltage-induced current through the material. Dielectics are subjected to very high electrical fields up to $10^{7}$ volt $/ \mathrm{cm}$. Thus a very high resistivity material is chosen of the order of $10^{14} \Omega$-cm. Besides the bulk resistivity the surface resistivity also plays an important role in determining the dielectric feasibility. In surface resistivity the surfaces are defected and provide fast charge diffusion paths leading to less resistivity compared to bulk. As dielectric films become thinner the surface to volume ratio increases which in turn leads to surface and interface electrical conduction mechanisms. Similarly interface between two metal layers and metal surfaces lead to increase in gross total resistance [29]. 
Coming to Bulk resistivity, it is seem to be influenced by:

(1) impurities, mostly by easily ionizable under bias ones like water, $\mathrm{H}^{+}, \mathrm{OH}^{-}, \mathrm{Na}^{+}$etc.;

(2) defects like point, line, area and volume are due to lower bulk resistivity

(3) stress affecting the band gap of the material.

(4) non-stoichiometry in some inorganic dielectrics will lead to higher vacancies.

(5) the ionic dielectrics generally have lower electrical resistance than covalently bonded.

(6) some ionizable covalent polymers due to the metal interface.

\subsubsection{2: $\underline{\text { Current leakage and Dielectric strengths }}$}

Ideally dielectric should be a perfect insulator but practically it has got some finite resistance. Some of the conduction mechanisms are discussed like

Poole-Frenkel emission [30]

$J=\mathrm{C}_{1} \mathrm{E} \exp \left[-\mathrm{q}\left\{\phi_{\mathrm{B}}-\sqrt{ }\left(\mathrm{q} E / \pi \epsilon_{I L D}\right) / K T\right\}\right]$

Fowler-Nordheim tunneling [29], $J$ is given by

$J=\mathrm{C}_{2} \mathrm{E}^{2} \exp -\left(\mathrm{E}_{0 \mathrm{e}} / \mathrm{E}\right)$

Where $\mathrm{C}_{1}, \mathrm{C}_{2}$, and $\mathrm{E}_{0}$ are constants, $q$ is electronic charge, $\phi_{\mathrm{B}}$ the barrier height, $E$ is the electric field, $K$ is the Boltzmann's constant, and T the temperature in Kelvin. Poole-Frenkel is observed only in heavily damaged insulators for field-enhanced excitation of trapped electrons into the conduction band, Whereas Fowler-Nordheim conduction is observed for electrons tunneling from metal Fermi level into the insulator (oxide) conduction band. These two mechanisms best describe the current leakage behavior in insulators. The Fowler-Nordheim 
tunneling is independent of temperature but the Poole-Frenkel is temperature dependent.

The leakage current capability is defined in terms of the maximum voltage (or the electric field which is voltage per unit thickness of the dielectric) that an ILD can sustain without leading to runaway currents (Current per unit area $\mathrm{A} / \mathrm{cm}^{2}$ ) called dielectric strength defined in the unit of volt/cm. For ILD application the dielectric strength of $2-5 \mathrm{MV} / \mathrm{cm}$ is considered as feasible. Figure 1.4 shows the schematic of current density vs. Electric field [1].

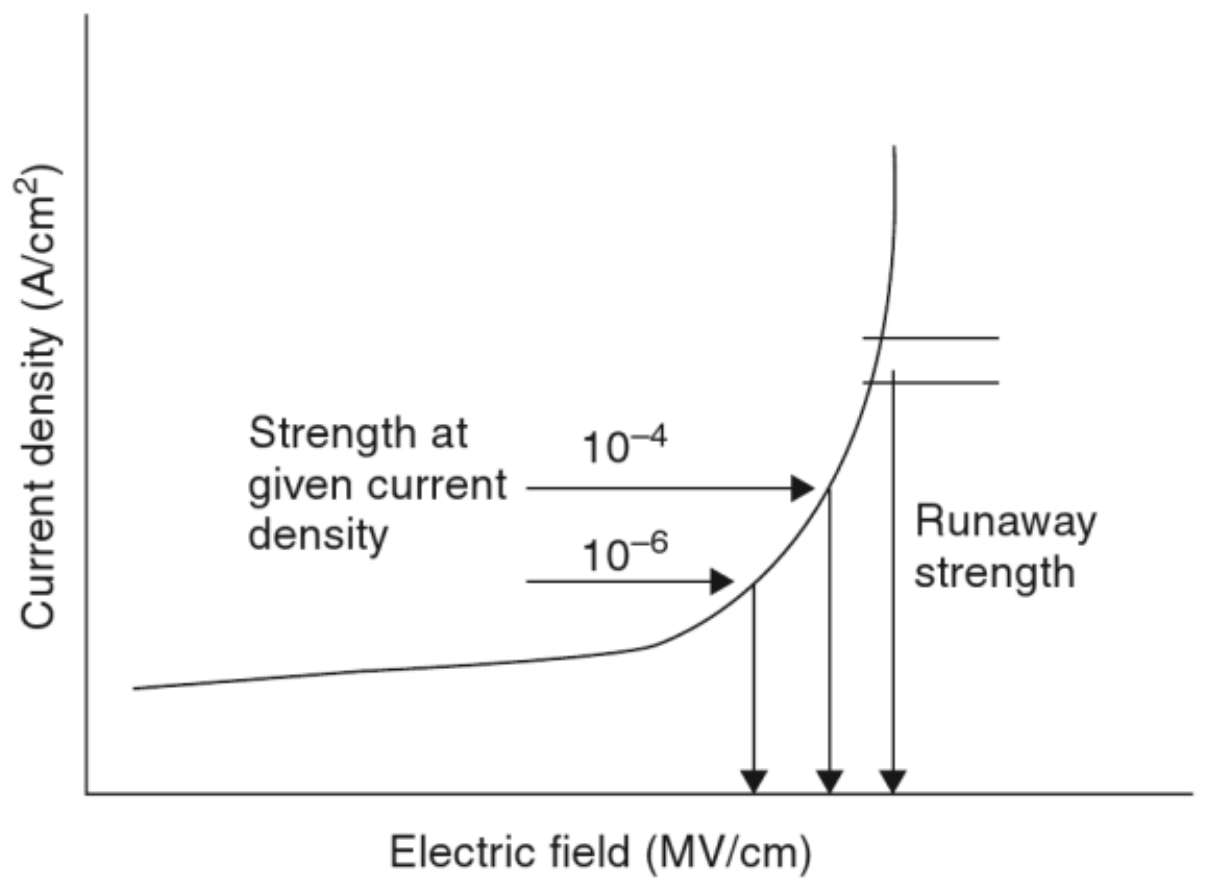

Figure 1.4: Schematic representation of current density through a dielectric as a function of the applied field.

Dielectric strength is related to the dielectric constant. The Dielectric constant of the inorganic dielectrics is shown in figure 1.5 [31]. It shows that lowest the dielectric constant higher is the field strength of a given dielectric. 


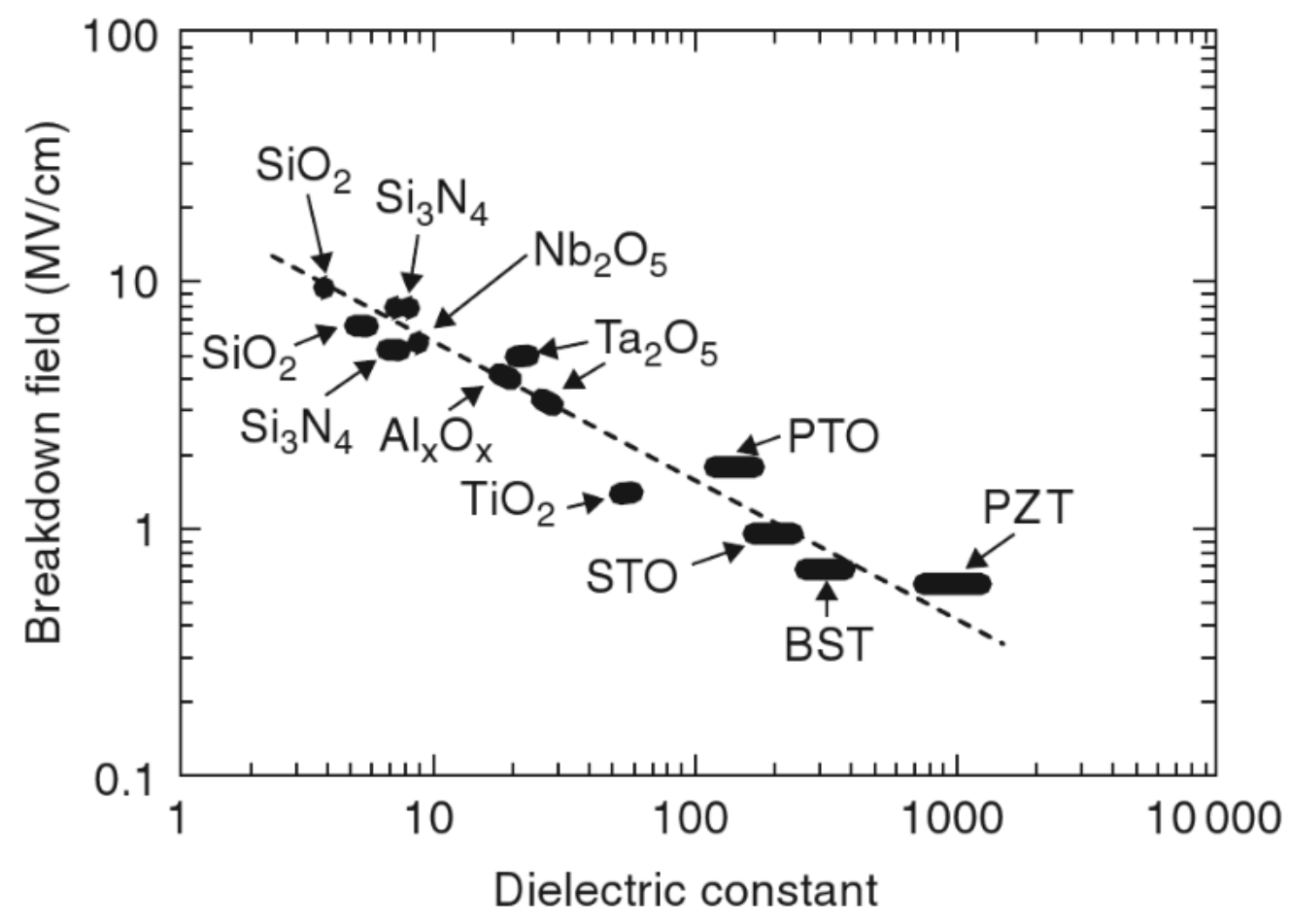

Figure 1.5: A log-log plot of the dielectric breakdown field (or field strengths), as a function of dielectric constant of dielectric.

Finally, it is noted that the dielectric breakdown field strength has dielectric-thickness dependence and decreases with the thickness. The lowering of the field strength at higher thickness is due to defects and also may be because of low thermal conductivities of the dielectric, the heating effectively raising the temperature more in thicker dielectrics than in thinner ones. Higher the temperature lower is the field strength and drop in the field strength at high temperatures could be very large. 


\subsubsection{3: Polarization and charges in the dielectric}

Polarization $(\alpha)$ occurs in dielectric when an electric field is applied across a dielectric. All dipoles are aligned with applied field (permanent dipoles and field induced ones). Polarizations fall under the following categories (a) electronic, (b) atomic or ionic; (c) orientation; and (d) space-charge polarizations. The total polarizibility is equal to the sum total of all the polarizations. The electronic and ionic polarizations are related with induced field displacement of electrons in an ion with respect to nucleus and positive and negative ions in an ionic dielectric respectively. The orientation and space charge polarizations are due to filed induced alignment of existing dipoles and existing mobile charges at the defective sites such as interfaces etc. Polarizability is given by Clausius-Mosotti equation [32].

$\alpha=(3 / 4 \pi \mathrm{N})\{(\mathrm{k}-1) /(\mathrm{k}-2)\}$

Where $N$ is the number of molecules per unit volume and $k$ is the dielectric constant. Also we know that the dielectric constant is given by

$\mathrm{k}=\epsilon / \epsilon_{0}$

Where $\epsilon$ and $\epsilon_{0}$ are the dielectric permittivities of the dielectric under consideration and that of Vacuum respectively. Hence by clubbing the above two equations we get

$\mathrm{k}=\{3 /(1-(4 \pi \mathrm{N} \alpha / 3)\}-2$

From the above equation we can conclude that higher the value of $N$ or $\alpha$ higher is $k$. Therefore for low-k materials, they are fabricated either from larger molar volume or lower polarization materials. Hence smaller atoms/ions (eg C, B, H) have comparatively lower $\alpha$ and lower is the 
value of $k$. This also concludes that higher the atomic number higher is the polarizibility and eventually higher value of $k$ [33].

\subsubsection{4: Dielectric dissipation and loss}

Regular dielectric the voltage lags current by $90^{\circ}$ but practically it lags by $\left(90^{\circ}-\delta\right)$ where $\delta$ is dielectric loss angle which leads to power loss in the form of heat. The dissipation of energy is defined now as follows.

(a) Dissipation factor $=\tan \delta$

(b) Dielectric loss factor $=k \tan \delta$.

Power loss $($ watt $)=5.56 \times 10^{-11} E^{2} \mathrm{fv} \mathrm{k} \tan \delta$

Where $E$ is the applied field strength in volts per meter, $f$ the frequency in hertz and $v$ the volume. Therefore to reduce the energy dissipation from a given material, we have to find lowest $\delta$. Under AC conditions it should be noted that

(a) Polarizations and loss are frequency dependent

(b) Electronic polarizations dominate at higher frequencies $\left(>10^{12} \mathrm{~Hz}\right)$

(c) Amorphous dielectric materials polarize at higher frequencies than the crystalline materials of same composition. 


\section{2: $\underline{\text { Overview }}$}

There exist atomic bonding similarities amongst boron, carbon, and nitrogen that allow the formation of compounds with a wide compositional range. $\mathrm{BCN}$ compounds have been expected to combine the excellent properties of $\mathrm{B}_{4} \mathrm{C}, \mathrm{BN}$ and $\mathrm{C}_{3} \mathrm{~N}_{4}$, with their properties adjustable, depending on composition and structure [3]. As graphite is semi metallic and h-BN is insulating (band gap $>3.8 \mathrm{eV}$ ), it is expected that such a hybrid between semi metallic graphite and insulating h-BN may show adjusted semiconductor properties [4]. Moreover, recent efforts have been devoted to develop a low dielectric constant $\mathrm{BCN}$ film in order to reduce the stray capacitance induced signal delay of interconnections in Si ultra large scale integrated circuits (ULSI). Dense (pore-free) BCN films with a low dielectric constant in the range of 1.9 to 2.1 have been successfully demonstrated [5]. The use of BCN films in the CMOS back end technology is really very interesting and promising. A material with a low dielectric constant and with high mechanical hardness is a perfect match for inter layer dielectrics. Several methods of preparing boron carbon nitride films have been reported, such as chemical vapor deposition (CVD), plasma assisted CVD, pulsed laser ablation, ion beam deposition, and sputtering. Also, shock wave compression or high pressure/high temperature techniques (HP/HT) have been used. The limitations in composition arise and are due to experimental restrictions like target composition or precursor mixing, so that one element is always incorporated in approximately the same while other two can be varied over a greater range.

The sputtering technique provides unique advantages over other techniques such as freedom to choose the substrate material and a uniform deposition over relatively large area. Furthermore, it is possible to control the deposition parameters to prepare $\mathrm{BCN}$ films of various 
compositions. According to the chemical properties of the $\mathrm{B}, \mathrm{C}$ and $\mathrm{N}$ during the depositing process of the $\mathrm{BCN}$ films, $\mathrm{B}$ and $\mathrm{C}$ can exist both as elements and as compounds reacting with $\mathrm{N}$ or each other, while $\mathrm{N}$ could be existed in the films only as compounds by reacting with B or C. Therefore, the process of $\mathrm{N}$ deposited into the films and the reciprocity among $\mathrm{B}, \mathrm{C}$, and $\mathrm{N}$ during the deposition of films becomes the main factors, which affect the composition and properties of films.

For low carbon content the $\mathrm{h}-\mathrm{BN}$ is preserved in boron carbonitride compounds. By increasing the carbon content towards $\mathrm{BCN}$ stoichiometry $(1<\mathrm{x}>2)$ the hexagonal stacking sequence tends into a fullerene-like structure. Increasing the carbon content to the composition $\mathrm{BC}_{4} \mathrm{~N}$, the sample exhibits an amorphous structure. A ternary compound of boron carbonitride $(\mathrm{BCN})$ has gained increased attention due to its potential applications in electronic, optoelectronic and luminescent devices. The boron-carbon-nitrogen phase diagram contains interesting phases, such as diamond, graphite, fullerene, cubic- $\mathrm{BN}, \mathrm{B}{ }_{4} \mathrm{C}$ and there is also a hypothetical $\mathrm{C}_{3} \mathrm{~N}_{4}$ as shown in Fig 1.4.

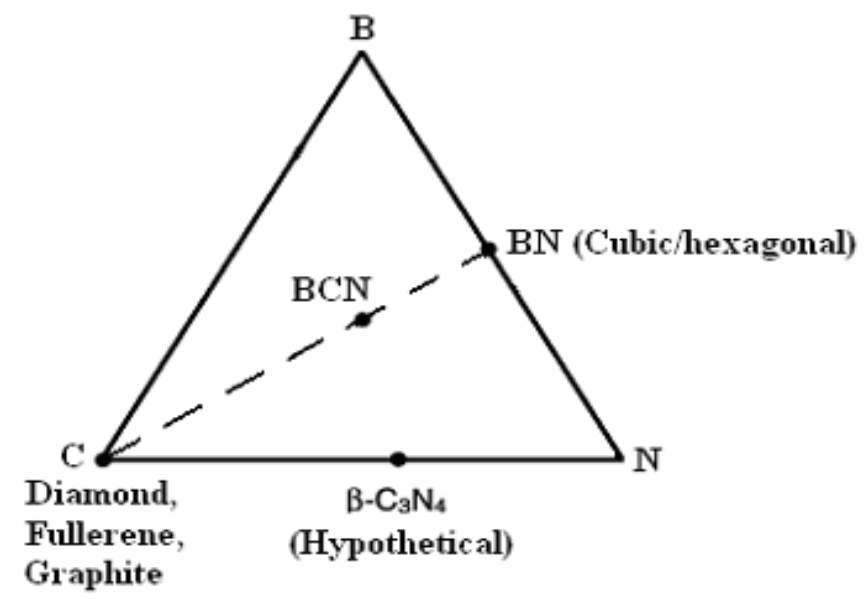

Figure 1.6: Ternary Triangle [34] 
Carbon nitride (C-N) thin films are predicted to have hardness comparable to diamond due to the small bond length and low ionicity of this material. The focus of this work was to synthesize the boron carbon nitrogen $(\mathrm{BCN})$ through $\mathrm{Rf}$ sputtering and investigating its electrical properties and access its feasibility to use as a low- $\kappa$ material in the CMOS back end technology. 


\section{CHAPTER 2: LITERATURE REVIEW}

\section{1: Boron Carbide}

Boron carbide $\left(\mathrm{B}_{4} \mathrm{C}\right)$ is an extremely hard boron-carbon ceramic material used in tank armor, bulletproof vests, and numerous industrial applications. With a Mohs hardness of about 9.497, it is one of the hardest materials known, behind cubic boron nitride and diamond [7]. The ability of boron carbide to absorb neutrons makes it an absorbent for neutron radiation arising in nuclear power plants. Nuclear applications of boron carbide include shielding, control rod and shut down pellets. Within control rods, boron carbide is often powdered, to increase its surface area. Electrically, boron carbide is p-type semiconductor material at even high temperatures which suggests is thermally very stable. In thin film form too, this material finds applications as hard and protective coatings, hard disk drives and other corrosion-resistance applications [8]. Sputtering techniques have been commercialized more successfully in big manufacturing fabs because of their high film deposition rate and low temperature features.

The chemical formula of boron carbide is $\mathrm{B}_{4} \mathrm{C}$. But some time there exist a deficiency in Carbon. Hence the formula is somewhere between $\mathrm{B}_{12} \mathrm{C}_{3}$ and $\mathrm{B}_{12} \mathrm{C}_{2}$. Boron carbide has a complex crystal structure typical of icosahedron-based borides as shown in figure 2.1. [9] 


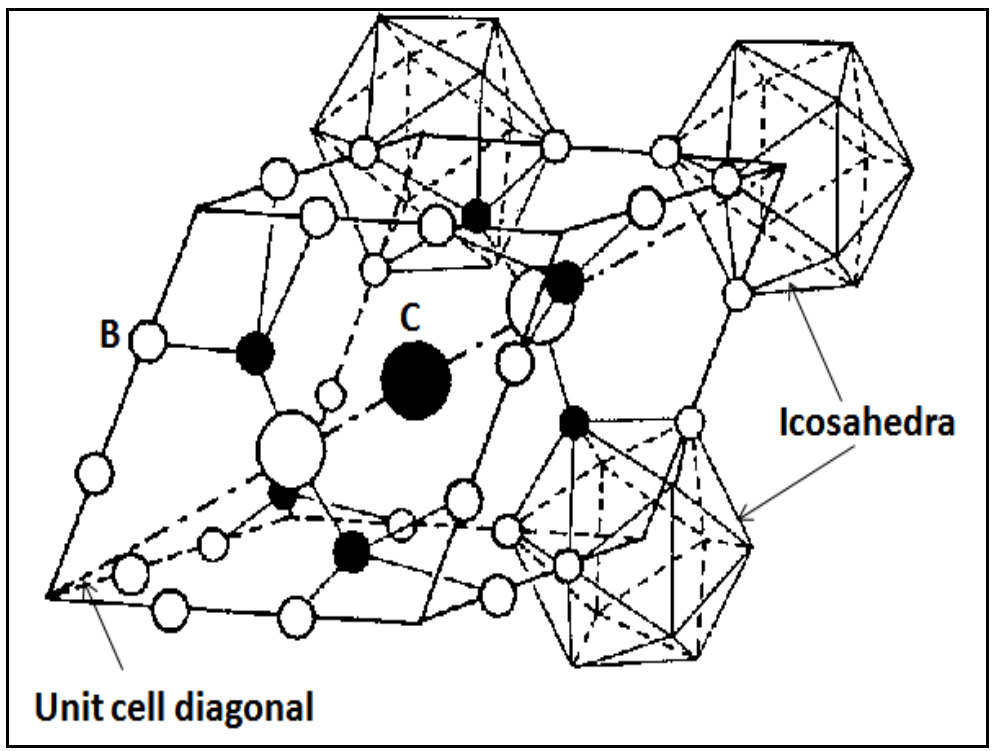

Figure 2.1: Icosahedron shape of unit cell of boron carbide. [10]

Boron carbide has the band gap of 1.2-1.8 eV [11]. But according to the literature it is given that the conductivity of Boron carbide is highest at $13 \%$ carbon percentage in the Boron carbide and later it decreases as and when the carbon content increases in the composition [9]. All sputter deposited thin films of boron carbide reported in the literature are amorphous. The boron carbide is very stable at high temperature as it has very high melting point and hence it is desired to be used at high temperatures in the form of an electronic device at inhospitable situations. In some work it is reported that amorphous hydrogenated boron carbide thin films with boron concentrations varying from 0 through $18 \%$ by plasma decomposition of a feedstock of diborane and methane. They found out that boron acts like a dopant with increase in boron concentrations which leads to increase in acceptor densities. Similar work on amorphous hydrogenated carbon doped with boron was first done by Jones and Stewart and they reported an increase by a factor of ten in conductivity [12]. The electrical conductivity was measured for 
boron carbide films that had boron to carbon ratio from 4.7 to 19.0 , for temperatures from room temperature to $100^{\circ} \mathrm{C}$. The electrical conductivity found to vary exponentially with reciprocal temperature. This shows that there is a little variation in conductivity as a function of Carbon composition. Hence it has been concluded that the electrical conductivity depends in the sample purity and preparation and the number of free carbon present in a given composition [13].

Table 2.1: General properties of boron carbide [16, 17].

Properties of boron carbide

Molecular weight $(\mathrm{g} / \mathrm{mol})$

55.26

Density $\left(\mathrm{g} / \mathrm{cm}^{3}\right)$

2.52 for $\mathrm{B}_{4} \mathrm{C}$

Melting Point $\left({ }^{\circ} \mathrm{C}\right)$

$\sim 2400$

Specific Heat (Cal/mol K at $300 \mathrm{~K}$ )

12.7

Thermal conductivity (W/cm K)

$0.35-0.16\left(25-800^{\circ} \mathrm{C}\right)$

Thermal expansion (1/K)

$4-8 \mathrm{E}^{-6}\left(25-800^{\circ} \mathrm{C}\right)$

Electrical Resistivity $(\Omega-\mathrm{cm})$

5 (at 298K)

Electrical conductivity (1/ $\Omega$-cm)

$\sim 10^{3}$

Band Gap (eV)

$0.77-1.80$

Dielectric Constant 5

Seeback coefficient $(\mu \mathrm{V} / \mathrm{K})$

200-300

Vickers Hardness (GPa)

27.4-40

Young's Modulus (GPa)

290-460

Shear Modulus (GPa)

$158-200$

Bulk Modulus (GPa)

190-250

Tensile Strength $\left(\mathrm{N} / \mathrm{mm}^{2}\right)$

$155\left(980^{\circ} \mathrm{C}\right) 162\left(1425^{\circ} \mathrm{C}\right)$ 
Properties of boron carbide

Poisson's Ratio

Flexural Strength (MPa)

Lattice constant ( $\mathrm{nm}$ )

Oxidation resistance

Chemical resistance
0.14-0.18

$323-430$

$c=1.207 \mathrm{a}=0.561$

in air up to $600^{\circ} \mathrm{C}$

Excellent. Reacts with

halogens at high temperature.

\section{2: Boron Nitride}

Boron nitride is very similar to diamond and can be used to make crystals that are as hard as diamond. Boron nitride is an excellent conductor of heat in spite being an insulator electrically. Boron nitride is mostly found in cubic (c-BN or $\beta-\mathrm{BN})$ and hexagonal (h-BN) phases. $\mathrm{BN}$ in general is not found naturally. Cubic $\mathrm{BN}$ has properties close to diamond and is known to be the second hardest material after diamond. Also, c-BN can be made either $\mathrm{n}$ or $\mathrm{p}$ type conductivity for electronic applications. On the other hand h-BN is a soft material with insulating properties and has a band gap of $5 \mathrm{eV}$. Cubic boron nitride is one of the physical forms of boron nitride and is made of tetrahedral bonded light elements. $\mathrm{BN}$ is also known as c-BN, $\beta$ $\mathrm{BN}$ or $\mathrm{z}-\mathrm{BN}$. The application of powdered form of $\mathrm{c}-\mathrm{BN}$ in industrial abrasive and boron nitride deposits are used to minimize friction and wear. Techniques used to prepare cubic boron nitride are physical vapor deposition (PVD), plasma enhanced chemical vapor deposition (PECVD), pulsed laser deposition, DC and RF magnetron sputtering from conductive and non-conductive targets (h-BN, boron, $\mathrm{B}_{4} \mathrm{C}$ composite). 
Also, c-BN can easily be doped n-type using $\mathrm{Si}$ and p-type using Be and $\mathrm{Mg}$. This is something that cannot be achieved with diamond. Lastly, c-BN does not react with foreign materials at high altitudes and in harsh environments [14]. It has a very large indirect energy band gap $\mathrm{E}_{\mathrm{g}}$ varying between 5.4 and $7.0 \mathrm{eV}$ at room temperature. Hexagonal boron nitride (h$\mathrm{BN}$ ) or $\alpha-\mathrm{BN}$ or g-BN (graphite $\mathrm{BN}$ ) is used at both very low temperature and at high temperature as a lubricant and in situations where the electrical conductivity or chemical reactivity would be problematic. Boron nitride lubricants can be used even in vacuum for space applications as the lubricity mechanism does not contain water molecules which will be trapped between the layers. h-BN can be included in ceramics, alloys, resins, plastics, rubbers and other materials, giving them self-lubricating properties. Hexagonal boron nitride is stable at temperatures up to $1000^{\circ} \mathrm{C}$ in air, $1400^{\circ} \mathrm{C}$ in vacuum and $2800^{\circ} \mathrm{C}$ in inert gas thus is a material which has one of the best thermal conductivities of all electric insulators. Another important characteristic of h-BN is that it is fairly chemically inert and is not wetted by many melted materials (e.g. aluminum, copper, zinc and steels, germanium, silicon, glass and halide salts). Because of its excellent dielectric and thermal properties, $\mathrm{BN}$ is used in electronics as a substrate for semiconductors, microwave-transparent windows, and as a structural material for seals [15]. Thin films of boron nitride can be obtained by chemical vapor deposition from boron tricholoride and nitrogen precursors 
Table 2.2: Comparison of various properties of BN with those of other semiconductors [100].

\begin{tabular}{|c|c|c|c|c|c|c|}
\hline Parameter & $c-B N$ & $\mathrm{~h}-\mathrm{BN}$ & Diamond & 3C-SiC & GaAs & $\mathrm{Si}$ \\
\hline Lattice Constant (A) & 3.615 & $a=2.504$ & 3.567 & 4.358 & 5.65 & 5.43 \\
\hline Thermal expansion & 3.5 & $2.7,3.7$ & 1.1 & 4.7 & 5.9 & 2.6 \\
\hline \multicolumn{7}{|l|}{ Coefficient } \\
\hline Density $\left(\mathrm{gm} / \mathrm{cm}^{3}\right)$ & 3.487 & 2.28 & 3.515 & 3.216 & - & 2.328 \\
\hline Melting Point (oC) & $>2973$ & - & 3800 & 2540 & 1238 & 1420 \\
\hline Energy bandgap (eV) & 6.4 & 5.2 & 5.45 & 3.0 & 1.43 & 1.12 \\
\hline Electron mobility $\left(\mathrm{cm}^{2} / \mathrm{Vs}\right)$ & - & - & 2200 & 400 & 8500 & 1500 \\
\hline Hole mobility $\left(\mathrm{cm}^{2} / \mathrm{Vs}\right)$ & - & - & 1600 & 50 & 400 & 600 \\
\hline Dielectric constant & 7.1 & 5.06 & 5.5 & 9.7 & 12.5 & 11.8 \\
\hline $\operatorname{Breakdown}\left(\times 10^{5} \mathrm{Vcm}^{-1}\right)$ & $\sim 80$ & $\sim 80$ & 100 & 40 & 60 & 3 \\
\hline Resistivity $(\Omega-\mathrm{cm})$ & $10^{16}$ & $10^{10}$ & $10^{13}$ & 150 & $10^{8}$ & $10^{3}$ \\
\hline Thermal conductivity & 13 & - & 20 & 5 & 0.46 & 1.5 \\
\hline Absorption edge $(\mu \mathrm{m})$ & 0.205 & 0.212 & 0.20 & 0.40 & - & 1.40 \\
\hline Refractive index & 2.117 & 1.700 & 2.42 & 2.65 & 3.4 & 3.5 \\
\hline Hardness (kg/mm) & 9000 & - & 10,000 & 3500 & 600 & 1000 \\
\hline
\end{tabular}




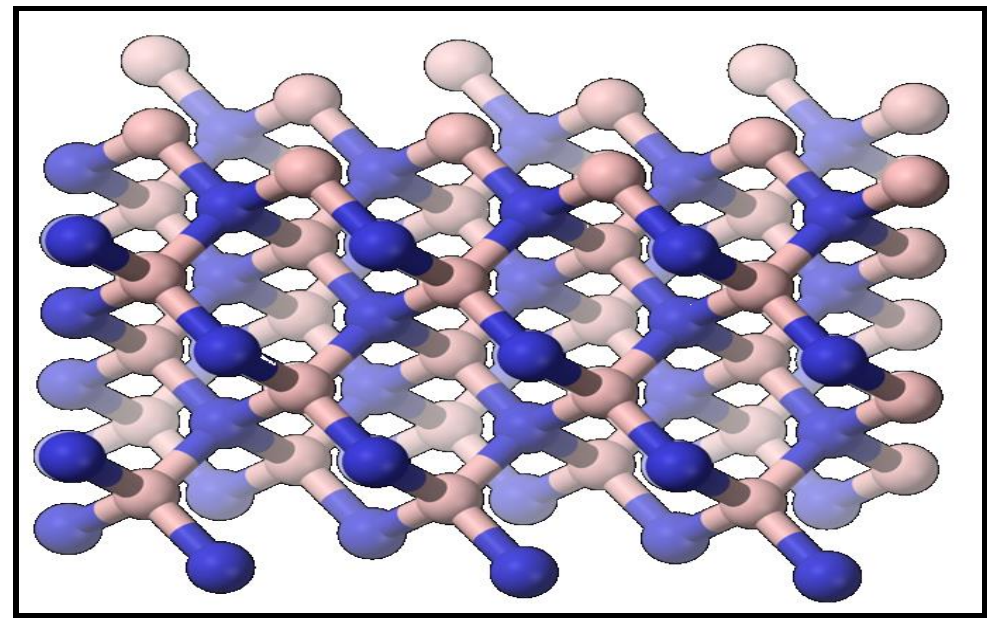

Figure 2.2: $\beta$-BN sphalerite structure

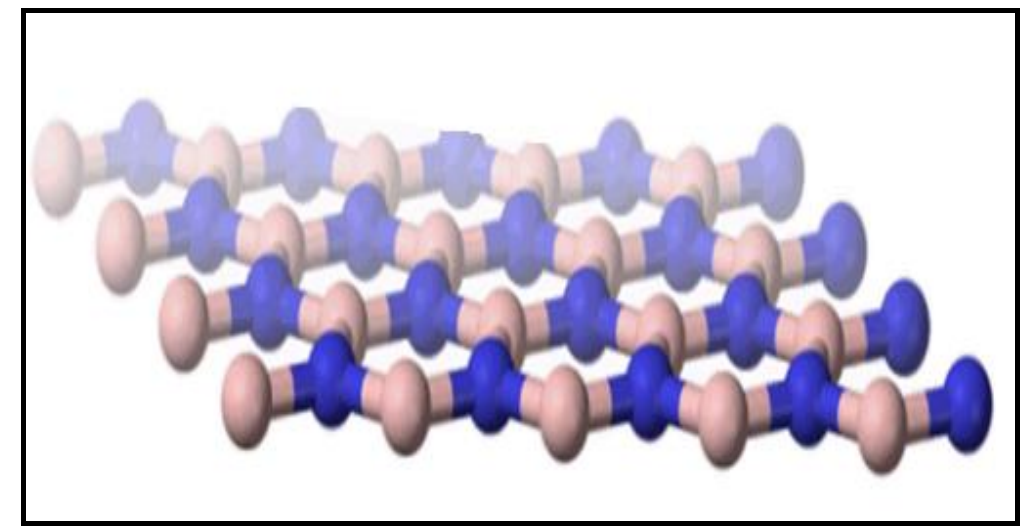

Figure 2.3: h-BN hexagonal (graphite like)

\section{3: Boron carbon Nitride}

The atomic sizes of boron, carbon and nitrogen are similar, also structures of carbon and boron nitride polymorphs are similar, it suggests that it is possible to produce diamond-like phase containing all three elements. Beginning in 1990, a great interest has been put in studying the possibility to synthesize dense B-C-N phases. They are expected to be thermally and chemically 
more stable than diamond, and harder than c-BN, and hence it would be used as materials for high speed cutting and polishing of ferrous alloys. These characteristic properties are because of diamond-like structure combined with the sp3 $\sigma$-bonds among carbon and the heteroatoms. $\mathrm{BC}_{\mathrm{x}} \mathrm{N}_{\mathrm{y}}$ thin films were synthesized by chemical vapor deposition in 1972. It is unclear whether the synthesis products are diamond-like solid solutions between carbon and boron nitride or just mechanical mixtures of highly dispersed diamond and c-BN. Ternary B-C-N phases can also be made using shock-compression synthesis. It was further suggested to extend the $\mathrm{B}-\mathrm{C}-\mathrm{N}$ system to quaternary compounds with silicon included. The phase diagram of the B-C-N is showed in Figure 1.6. One of the characteristic features of the materials in the $\mathrm{BCN}$ ternary phase system is that they have short bond lengths and thus expected to combine the specific properties of diamond, cubic boron nitride (c-BN), hexagonal boron nitride (h-BN) and boron carbide $\left(\mathrm{B}_{4} \mathrm{C}\right)$.

The boron-carbon-nitrogen phase diagram contains interesting phases, such as diamond, graphite, fullerene, cubic- $\mathrm{BN}, \mathrm{B}_{4} \mathrm{C}$ and there is also a hypothetical $\mathrm{C}_{3} \mathrm{~N}_{4}$. Also, the ability to control the band gap $(\mathrm{Eg})$ by changing the atomic composition and structure makes them suitable for the application in electronic and photonic devices [16]. Different deposition techniques have been reported for depositing $\mathrm{BCN}$ thin films, including chemical vapor deposition (CVD), ion beam assisted deposition, cathodic arc plasma deposition, pulsed laser deposition, DC and RF magnetron sputtering. The experimental investigations reported above focuses mainly on the synthesis, characterization and mechanical properties. A group deposited BCN films by plasmaassisted chemical vapor deposition and studied the optical and electrical properties. They concur that the carbon composition had a good dependence on the optical and electrical properties of the BCN films. The band gap of the film decreased from 5.3 to $3.4 \mathrm{eV}$ with increase in Carbon 
composition ratio from 9 to $30 \%$. The electrical resistivity of the $\mathrm{BCN}$ film decreases from $1 \times 10^{12}$ to $3.4 \times 10^{9} \Omega-\mathrm{cm}$ as the carbon content in the films increased from 9 to $30 \%$ [5]. The electrical properties of $\mathrm{BC}_{2} \mathrm{~N}$ thin films with respect to temperature were found out and it was reported that there was a dependence of resistivity and Hall Effect measurements. The resistivity and Hall Effect measurements results indicated that $\mathrm{BC}_{2} \mathrm{~N}$ thin films are p-type semiconductors and the acceptor levels were between 7.5 and $23 \mathrm{meV}$. They also studied the dependency of type of substrate and found that the quality of thin film is better on Ni substrates than on quartz [17]. Other group reported the growth of $\mathrm{c}-\mathrm{BCN}$ thin films by reactive pulsed laser ablation (RPLA). They used a rotating target consisted of two semi disks wherein one of h-BN and other one of graphite and this deposition was done at room temperature. They observed crystalline BCN films with the formation of c-BCN, h-BCN and h-BN. The films were hard, adherent and transparent. $\mathrm{BCN}$ films were also prepared by pulsed laser deposition from a sintered $\mathrm{B}_{4} \mathrm{C}$ target. The films prepared were found to be smooth and adhered well to the substrate. They also observed that with the help of reactive nitrogen plasma they can incorporate more amounts of nitrogen in the films.

BCN thin films deposited using sputtering and the work on it is discussed from now on. One of the work reports that they prepared $\mathrm{BCN}$ films by $\mathrm{RF}$ reactive sputtering from a hexagonal h-BN target in an $\mathrm{Ar}-\mathrm{CH}_{4}$ discharge. They made different films with different carbon contents by varying the $\mathrm{CH}_{4}$ partial pressure. Under optimum processing conditions they observed polycrystalline $\mathrm{BC}_{2} \mathrm{~N}$ and the calculated activation energy was approximately $0.8 \mathrm{eV}$ [17]. BCN films were also deposited by RF magnetron sputtering using a composite target consisting of h-BN and graphite in an $\mathrm{Ar}-\mathrm{N}_{2}$ atmosphere. They studied the effect of sputtering 
power on the composition of BCN films and found that the films deposited at $80 \mathrm{~W}$ and $130 \mathrm{~W}$ are close to the $\mathrm{BC}_{2} \mathrm{~N}$ stoichiometry and the sample deposited at $110 \mathrm{~W}$ is close to the stoichiometry of BCN.

Lastly the samples deposited at $100 \mathrm{~W}$ and $120 \mathrm{~W}$ have the chemical composition of $\mathrm{BC}_{2} \mathrm{~N}$. Thus they were able to achieve the $\mathrm{BCN}$ films with different compositions by varying the power to the composite target [18]. Dual cathode magnetron sputtering was used to deposit BCN films by Kusano et al. and they sputtered from graphite and boron targets. They varied the power to the sputtering targets and concentration of nitrogen gas in the sputtering chamber. They observed the variation of deposition rate with reactive gas and the $\mathrm{BCN}$ films deposited at pure nitrogen exhibited a higher content of $\mathrm{sp}$ and $\mathrm{sp}^{2}$ carbon and had lower durability in friction tests as compared to other $\mathrm{BCN}$ films. Another group reported that $\mathrm{BCN}$ thin films near $\mathrm{B}_{4} \mathrm{C}$ composition deposited by radio frequency magnetron sputtering from a sintered $\mathrm{B}_{4} \mathrm{C}$ target. They observed the increase in nitrogen incorporation in the films from 0 to 40 at. $\%$ while the relative atomic composition of $\mathrm{B} / \mathrm{C}$ was relatively constant at 4 thus the films structure changed from $\mathrm{B}_{4} \mathrm{C}$ to a mixture of $\mathrm{h}-\mathrm{BN}$ and amorphous carbon. Same group of researchers characterized $\mathrm{BCN}$ films by their micromechanical and micro tribological behavior. They evaluated the adhesion and friction coefficient against diamond by micro scratch and also characterized their wear behavior at the nano metric scale. They found that the hardness is higher in the films with lower nitrogen concentration and the least hard films had nitrogen content of around 20 at.\% [19]. Some work on dielectric constant studies was also performed by many groups. Takashi et al the dielectric constant of $\mathrm{BCN}$ is found to decrease with decrease in growth temperature. The dielectric Constant is estimated from the accumulation region of capacitance-voltage $(\mathrm{C}-\mathrm{V})$ 
characteristics of $\mathrm{Au} / \mathrm{BCN} / \mathrm{p}-\mathrm{Si}$ samples. Reduction in the crystal grain size and increase of the amorphous region of The $\mathrm{BCN}$ films are observed with decreasing growth temperature. Here the Polycrystalline boron carbon nitride $(\mathrm{BCN})$ films are synthesized at various temperatures by plasma-assisted chemical-vapor deposition [20]. Also it has been reported by Sugino et al that boron nitride films with a dielectric constant as low as 2.2 can be synthesized by plasma-assisted chemical-vapor deposition (PACVD) [21]. It has been reported that the addition of C atoms to $\mathrm{BN}$ films is effective in reducing the dielectric constant.

\section{4: $\underline{\text { Carbon nitride }}$}

Liu and Cohen made theoretical prediction that $\beta-\mathrm{C}_{3} \mathrm{~N}_{4}$ which is isomorphic with $\beta-\mathrm{Si}_{3} \mathrm{~N}_{4}$ might have a bulk modulus which can exceed that of diamond [26]. Figure 2.4 shows the structure of the carbon nitride. This has triggered a lot of research work in the development of $\mathrm{C}_{3} \mathrm{~N}_{4}$ over the past two decades. C-N material along with high hardness also is expected to possess wide band gap, high thermal conductivity, high strength, high decomposition temperature and excellent resistance to corrosion and wear. Carbon Nitride possesses applications for insulator devices in III-V metal-insulator-semiconductor structures. $\mathrm{C}-\mathrm{N}$ is a preferred material over $\mathrm{Si}_{3} \mathrm{~N}_{4}$ for such applications because it doesn't introduce any shallow impurities. 


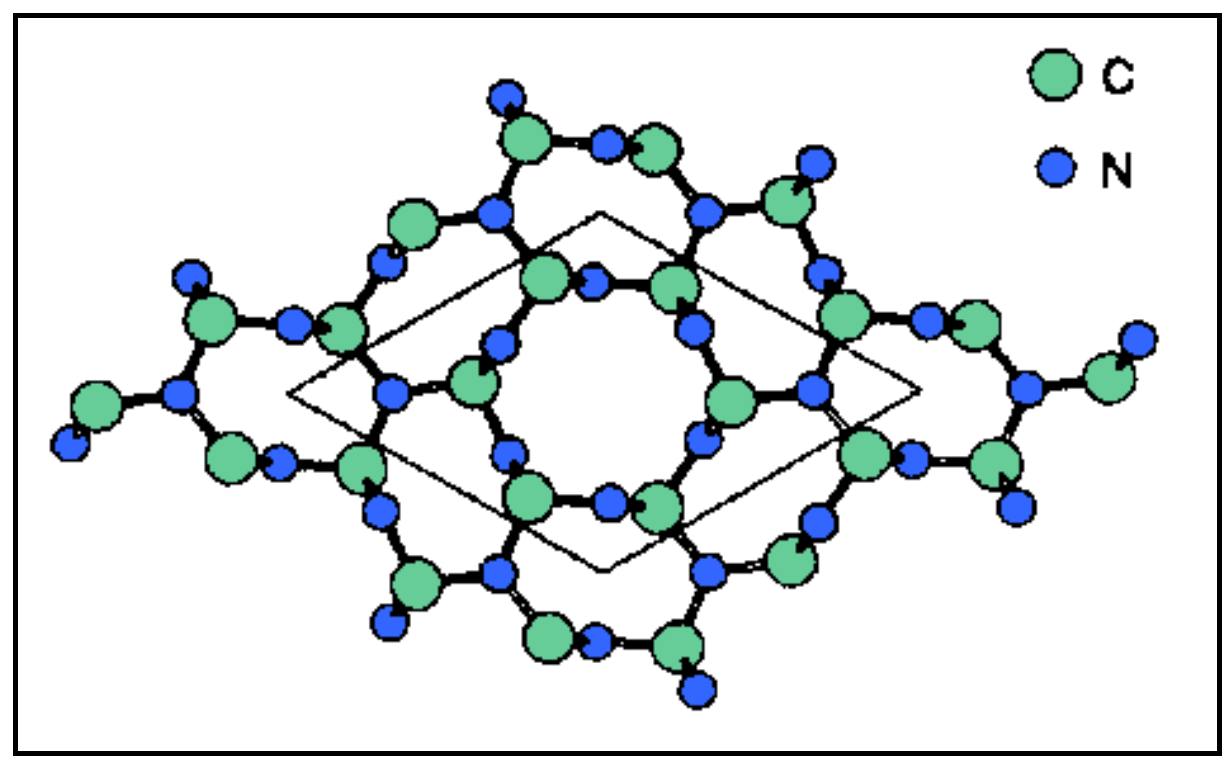

Figure 2.4: Crystal structure of carbon nitride

There have been many research reported on the deposition of $\mathrm{C}-\mathrm{N}$ films such as reactive sputtering, plasma chemical vapor deposition (CVD), laser ablation, ion-assisted deposition and metal-organic chemical vapor deposition (MOCVD). The incorporation of nitrogen in the C-N films was around $40 \%$ which is lesser than that expected for stoichemetric $\beta-\mathrm{C}_{3} \mathrm{~N}_{4}(57$ at $\%)$ in all the work reported above. Higher amounts of nitrogen (50-57 at. \%) has been reported in the hydrogenated $\mathrm{C}-\mathrm{N}$ films prepared by plasma CVD and the $\mathrm{CN}$ films obtained by dual ion beam sputtering, laser ablation of graphite using a low-wavelength excimer laser and by using the MOCVD technique [27]. The sputtering being the most commonly used method of deposition in the industry results in relatively low nitrogen content in the carbon nitride films [28]. One group performed reactive sputtering and observed the effect of nitrogen incorporation on the growth kinetics, composition, structure and type on bonding. They noticed that the incorporation of $\mathrm{N}_{2}$ in the plasma leads to an increase in the growth rate and that the growth kinetics and $\mathrm{N}$ content in 
the films is dependent on physical and chemical sputtering. The alteration in growth kinetics influenced the chemical, structural and optical properties. Another group also deposited C-N films by reactive sputtering and premised that by decreasing the target power and at high nitrogen pressure results in higher $\mathrm{N}_{2}$ contents in the film. They were able to gain equal amounts of carbon and boron for a wide range of sputtering pressures at low temperatures and the structure of the film obtained was graphite-like. 


\section{CHAPTER 3: METHODOLOGY}

In this chapter, the techniques and procedure for fabricating $\mathrm{BCN}$ devices for characterization and measurement purposes are conducted. This chapter also elucidates various materials and electrical characterization techniques used to study the thin film samples. Also it outlines briefly about different electrical measurements like I-V Characteristics, Capacitance measurements, Breakdown voltage measurements.

Sputter deposition technique was used to deposit thin film samples. Sputter deposition is a physical vapor deposition (PVD) method of depositing thin films by eroding material from a source, which in turn is deposited onto a substrate. The advantage of sputtering is that the deposited films have the same composition as the source material. The similitude of the film and target stoichiometry will be maintained because the sputter yield depends on the atomic weight of the atoms in the target. Magnetron sputtering was instrumental in getting strong electric and magnetic fields to trap electrons close to the surface of the target. Insulating targets can cause buildup of charges that is why biasing was varied in the anode and cathode with a radio frequency (rf) power source. Sputter deposition sources (also called sputter "guns") creates low pressure plasma by the excitation of an inert gas (typically argon) contained at 1 to 30 millitorr in a vacuum chamber. This process extracts energetic ions which accelerate toward the cathode target, striking it with kinetic energy up to several hundred electron volts. It then ejects material from the target with approximately $90 \%$ leaving as neutral atoms and $10 \%$ as ions as a result of energy transfer. Gas phase collisions between target atoms and argon atoms scatter the ejected material into a distributed cloud. As the cloud migrates towards the substrate, the random approach angles result in deposition of a uniform film, even on surfaces that have micron-sized 
vertical structures.

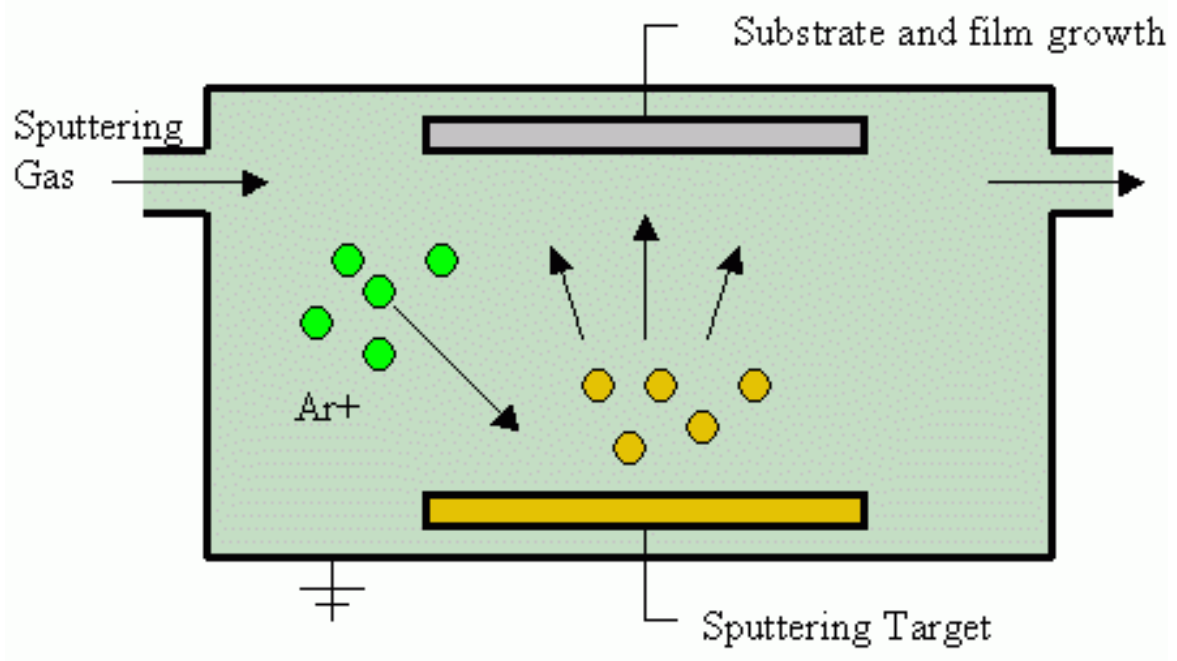

Figure 3.1: Sputtering Process Cartoon

Thin films of BCN were deposited by reactive RF magnetron sputtering in an Ultra High Vacuum system. Three inches, powder pressed, $\mathrm{B}_{4} \mathrm{C}$ target with a purity of $99.5 \%$ was used. The system base pressure was approximately $1 \times 10^{-8}$ Torr and the purity of the process gas were maintained by a hot reactive metal getter. Reactive sputtering was used where the deposited film is formed by chemical reaction between the target material and a gas which is introduced into the vacuum chamber. Oxide and nitride films are fabricated using this technique. The composition of the film is controlled by changing gas flow ratios of inert and reactive gases. In this case nitrogen was used as the reactive gas and, the $\mathrm{N}_{2}$ to Ar ratio was varied from 0.25 to 1 , in steps of 0.25 by changing the individual gas flow rate, while total gas flow was kept constant at $20 \mathrm{sccm}$ and the deposition pressures were varied between 2 mtorr and 5 mtorr. And for each ratio the deposition temperature was varied. The deposition temperatures used are room temperature, $200^{\circ} \mathrm{C}, 300^{\circ} \mathrm{C}$, $400^{\circ} \mathrm{C}, 500^{\circ} \mathrm{C}$. 


\section{1: Fabrication of MIM devices}

MIM stands for Metal-Insulator-Metal devices. The Corning glass was used as substrate to fabricate the MIM structure. The standard cleaning procedure was followed to clean the substrate that includes rinsing with acetone, methanol and DI (De-ionized) water. The substrate was then rinsed thoroughly with DI water, dried with Nitrogen gas jet and was loaded in to the sputtering chamber for subsequent $\mathrm{BCN}$ deposition. It is always good to make sure that there is no surface oxide before depositing the insulating film. The surface oxide if present will add an additional parasitic capacitance which may hinder the total capacitance value of the device.

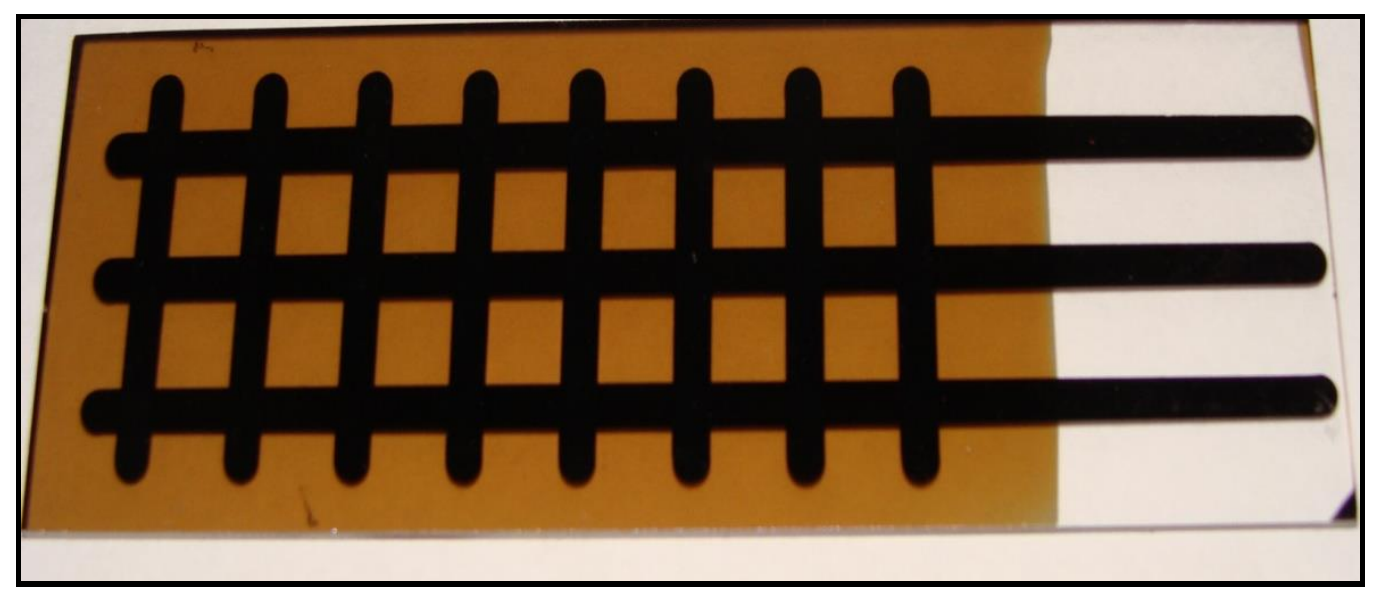

Figure 3.2: $\mathrm{MIM}$ structures (Al-BCN-Al) on a glass substrate

\subsection{1: Preparation of the base Al electrodes}

The Aluminum electrodes of $3 \mathrm{~mm}$ wide were deposited using a mechanical mask in a Vacuum Thermal evaporation system. During the deposition of Aluminum, the Thermal evaporation chamber was first roughed from atmosphere pressure to the pressure of 50mtorr with the help of a mechanical pump (Backup pump). Then by closing the mechanical pump, the foreline pump's valve is opened. Here we have used the Cryo pump as the Foreline pump. This 
Cryo pump helps in pumping down the system from 50mtorr chamber pressure to $1 \times 10^{-5}$ torr. It was found out from the earlier experiments that to get the high quality films with fewer defects, the pressure around $1 \times 10^{-5}$ torr would be required. The Aluminum strips were dangled on the tungsten filament in the chamber. The cleaned substrates were attached to the holder from the lid and it is closed and it is made sure that the substrates are facing the filament firming a minimal distance between the substrates and Al strips. The initial roughing is done to the chamber to achieve the pressure of 50mtorr and then the Cryo pump is used to bring down the pressure to 1 $\mathrm{x} 10^{-5}$ torr. Then the high current is passed from an induction coil current source by slowly incrementing the current from $0 \mathrm{~A}$ to $35 \mathrm{~A} .35 \mathrm{~A}$ is maintained for a minute for proper uniform deposition of $\mathrm{Al}$ on the substrate. After that another minute is left for degassing.

\subsection{2: Deposition of BCN thin films}

$\mathrm{BCN}$ film is sputter deposited on a glass substrate in a sputtering chamber. These were deposited from a 3 inch $\mathrm{B}_{4} \mathrm{C}$ target. The reactive sputtering was used to deposit $\mathrm{BCN}$ films. The base pressure of the chamber was achieved in the range of $2 \times 10^{-7}$ Torr. The $\mathrm{N}_{2} / \mathrm{Ar}$ gas flow ratio was varied in the steps of 0.25 from 0.25 to 1 , keeping the total gas flow in the sputtering chamber constant at $20 \mathrm{sccm}$. The R.F power of $200 \mathrm{~W}$ to the $\mathrm{B}_{4} \mathrm{C}$ target was kept constant. The depositions were done at 2 mtorr and 5mtorr partial pressures (Plasma pressure). The time for deposition was 1 hour for all the samples. The thickness of the BCN film was measured by $\alpha$ step Profilometer. The BCN thicknesses ranged from $900 \AA-2000 \AA$. The samples were deposited at a range of deposition temperatures from room temperature, $200^{\circ} \mathrm{C}, 300^{\circ} \mathrm{C}, 400^{\circ} \mathrm{C}$, $500^{\circ} \mathrm{C}$. Thermocouple attached to the substrate holder was used to measure the temperature of 
the substrate. The temperature was noted in steady state condition. The rotation speed of the substrate was set around $20 \mathrm{rpm}$. There are two steps for achieving the base pressure of $1 \times 10^{-7}$ torr. The samples are loaded into the load lock system attached to a substrate holder and it is pumped down (roughing) from atmospheric pressure to $5 \times 10^{-5}$ torr. Then the samples are introduced to the main chamber from the load lock system by opening the valve between them and the substrate holder with the samples are placed to a pre-set distance from the target. The target is placed facing the substrate holder at an angle of $45^{\circ} \mathrm{C}$. When the samples are positioned accordingly, RF power is started from $0 \mathrm{~W}$ to $200 \mathrm{~W}$ in small incremental steps and made sure the plasma is sustained for the rest of the sputtering process. The desired $\mathrm{N}_{2} / \mathrm{Ar}$ flow ratio is maintained and also the partial pressure in the chamber and the desired temperature is maintained as required. Now the sputtering is started in the chamber by opening the lid covering the target and it is left open for an hour of sputtering.

Lastly, aluminum electrodes of $3 \mathrm{~mm}$ width each running all through the length were deposited on the BCN layer to form the top layer electrode of the MIM structures using the Vacuum thermal evaporation method as explained previously. The substrates are dealt with same cleaning procedures before all three kinds of depositions. 


\section{2: Electrical Characterization}

Current-Voltage (I-V) measurement was performed on MIM devices fabricated with $\mathrm{BCN}$ as an insulator. This was used to measure the resistivity and breakdown voltage of the $\mathrm{BCN}$ films across top and bottom Aluminum electrodes formed as a Metal-Insulator-Metal (MIM) structure. The dielectric constant was also measured from the capacitance values obtained from the LCR meter knowing the thickness of the films deposited.

\subsection{1: I-V Characterization}

Current-Voltage measurement (I-V characteristics) was conducted with help of HP 4145B semiconductor parameter analyzer as shown in figure 3.3. This instrument was connected to a probing station. The samples were kept inside the probing station having two micro tip probes connected to the parameter analyzer. This parameter analyzer is interfaced to the computer. Hence all the measurements are performed through software interfaced computer. I-V characterization is done by taking the voltage sweep from $0 \mathrm{~V}$ to $40 \mathrm{~V}$ and subsequently the I-V characteristic graph is plotted. From the initial values of current response to the input voltage, the resistance of the film was found out. We found the resistance of the film and by observing the graph plot for sudden rise in current for a given voltage the breakdown voltage is noted down. By knowing the thickness of the deposited film and the line width of the deposited Al electrodes, the resistivity is found out. 


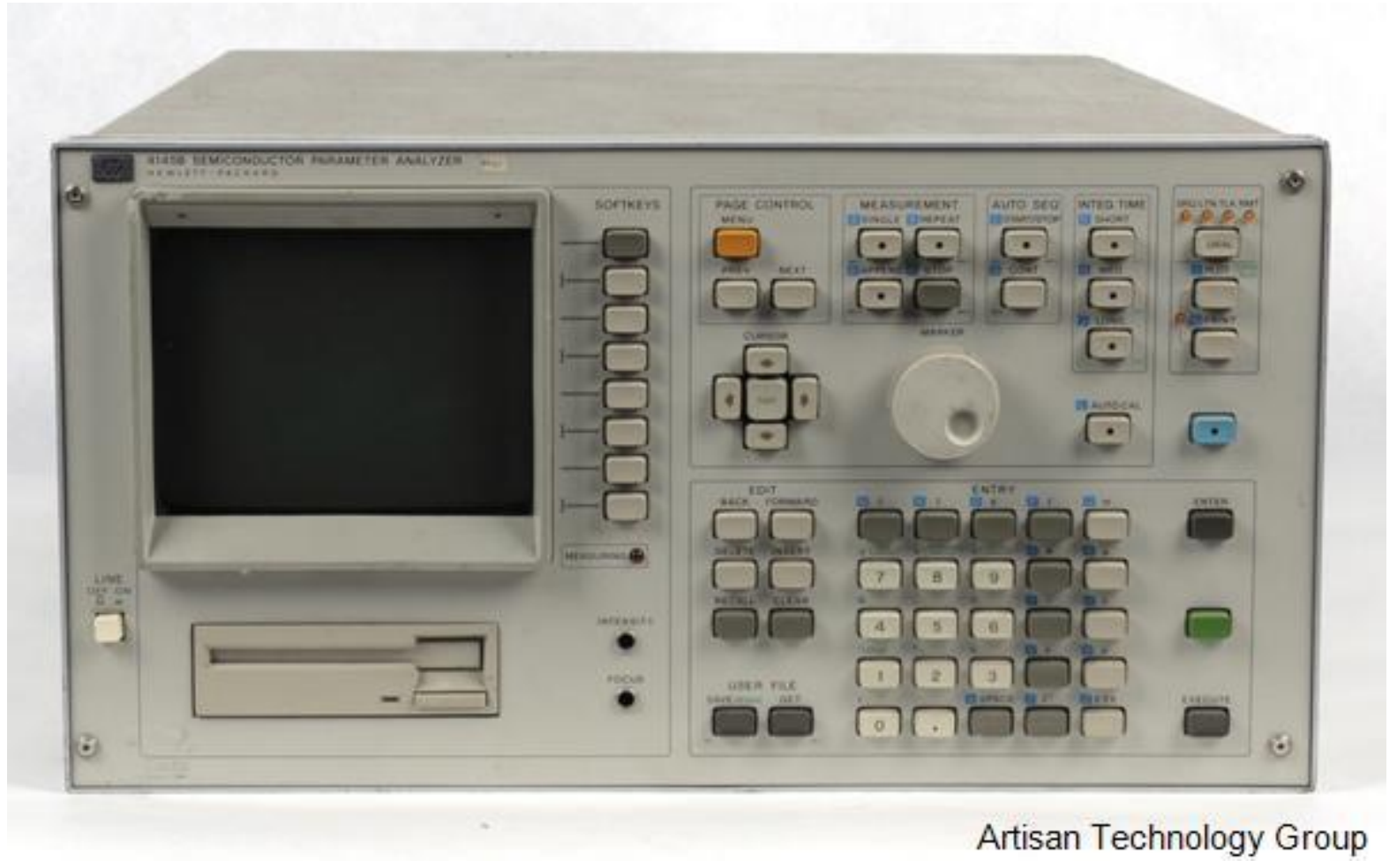

Figure 3.3: HP 4145B semiconductor parameter analyzer (Courtesy: Artisan Technology Group)

\subsection{2: Dielectric constant measurement}

The HP 4275A Multi-Frequency LCR meter is used to measure the capacitance of the MIM structures as shown in figure 3.4. This instrument was connected to the probing station and software interfaced to the computer. The frequency of operation of this measurement is $1 \mathrm{MHz}$ as the capacitance measured was in the range of couple of nano farads which is a small value of capacitance. The samples are kept in the same probing station and connected to the probes which in turn are connected to the LCR meter. Calibration is done before the measurement of capacitance for each device. By knowing the capacitance, the film thickness and the line width of the aluminum electrode the dielectric constant was found out. 


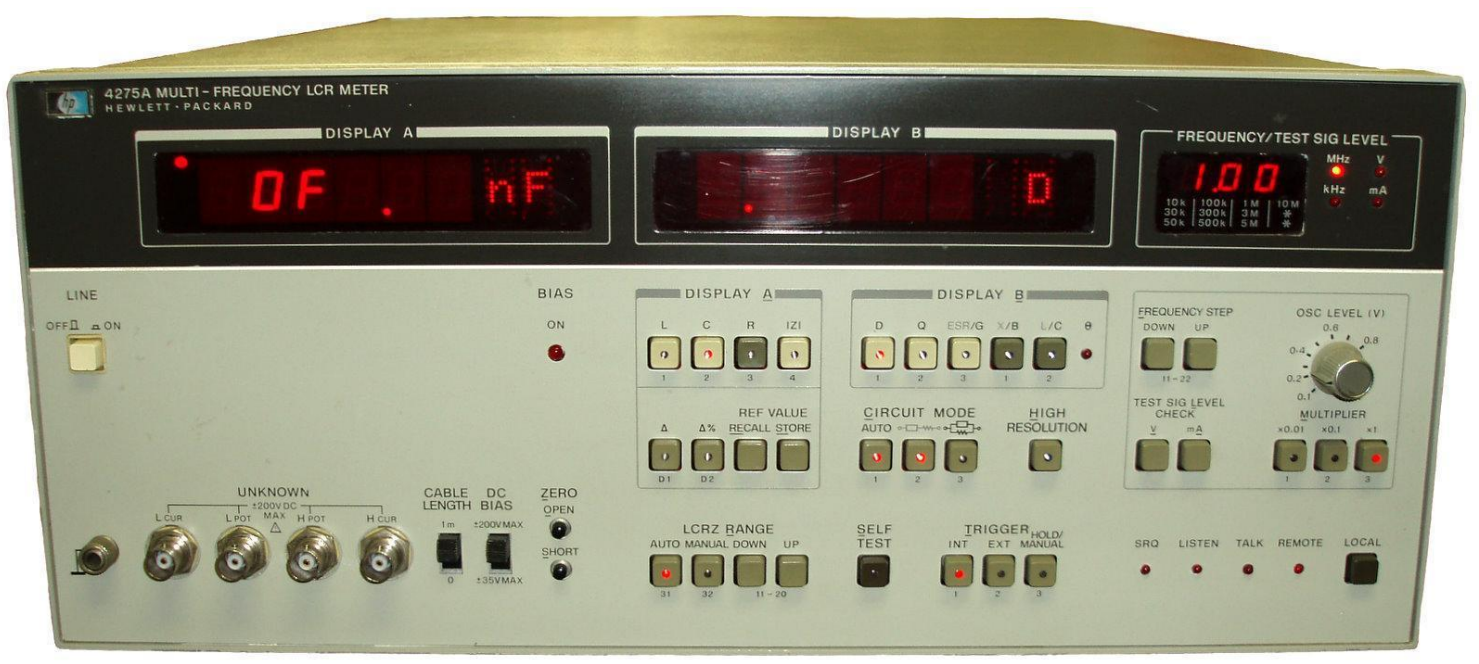

Figure 3.4: Dielectric constant measurement (Courtesy: Agilent Technologies)

\subsection{3: Thickness measurement}

The thickness measurement was done by Veeco Dektak 150 profilometer as shown in figure 3.5. It is a surface profilometer that takes surface measurements using contact profilometry techniques. The Dektak 150 uses stylus profilometry technology, which is the accepted standard for surface topography measurements, roughness and step size. Here its property of Twodimensional surface profile measurements is used to measure the step height. The step is created by masking a small portion on a test sample during the sputtering process using a thin strip of aluminum foil as it can withstand the high temperature and its property of less diffusivity into the BCN layer during the sputtering process. The scan length range used for measurement is $65 \mathrm{~mm}$ and the stylus force was $15 \mathrm{mg}$ for a scan time of 30 second. The software profiling is done after the mechanical profiling if the profile obtained is off level. Then the Average step height is found out by placing the two cursors on either sides of the step obtained in the profile. 


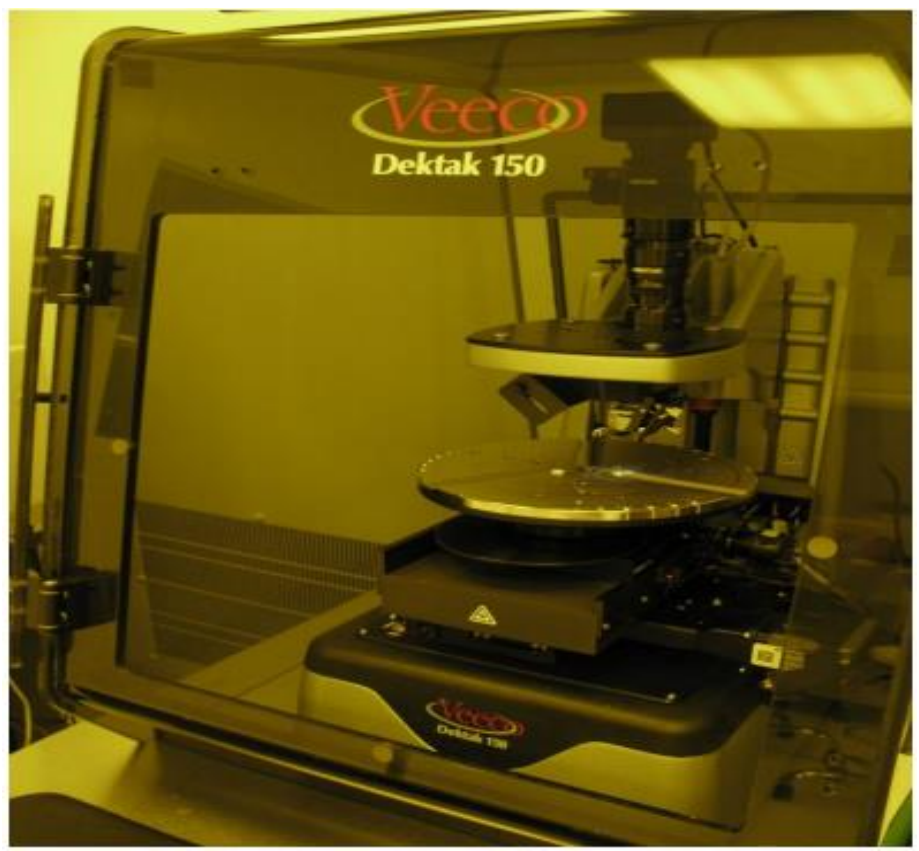

Figure 3.5: Veeco Dektak 150 profilometer (Courtesy: Veeco) 


\section{CHAPTER 4: RESULTS AND DISCUSSION}

\section{1: Electrical Studies}

In this section various electrical properties like dielectric constant, resistivity and Breakdown Voltage are found and their consequent relationship with respect to different physical parameters like gas flow ratios, partial pressures, deposition temperatures etc. are elucidated in terms of graph plots.

\subsection{1: Dielectric constant v/s deposition temperatures}

The figure 4.2 shows the plot of dielectric constant vs. Temperature of different samples for range of temperatures such as as-deposited, $200^{\circ} \mathrm{C}, 300^{\circ} \mathrm{C}, 400^{\circ} \mathrm{C}, 500^{\circ} \mathrm{C}$; for a deposition pressure of 2 mtorr. Different $\mathrm{N}_{2} / \mathrm{Ar}$ gas flow ratios of $0.25,0.5,0.75,1$. The capacitance was measured on eighteen different MIM devices formed on a single glass substrate. Then by knowing the line width of the electrodes and the film thickness of the deposited BCN thin film at a particular temperature with the help of $\alpha$-step profilometer, the dielectric constant is found out and their average values are plotted against the different temperatures. Figure 4.3 shows the Dielectric constant vs. Temperature plot at 5mtorr deposition pressure at various gas flow ratios. The dielectric constants of the samples tend to decrease with increasing temperature. This can be attributed to the fact that the film is more uniformly formed and is less amorphous at high temperature. Also it is reported in the literature that the increase in deposition temperature decreases the concentration of Carbon in the sample [22]. Also the dielectric constant of $\mathrm{B}_{4} \mathrm{C}$ is 
around 4.8 to 8 [24] and the dielectric constant of BN is around 3.9 to 4.3 [25]. Hence the sample shows a more of $\mathrm{BN}$ characteristics thereby having lower dielectric constant at higher temperatures.

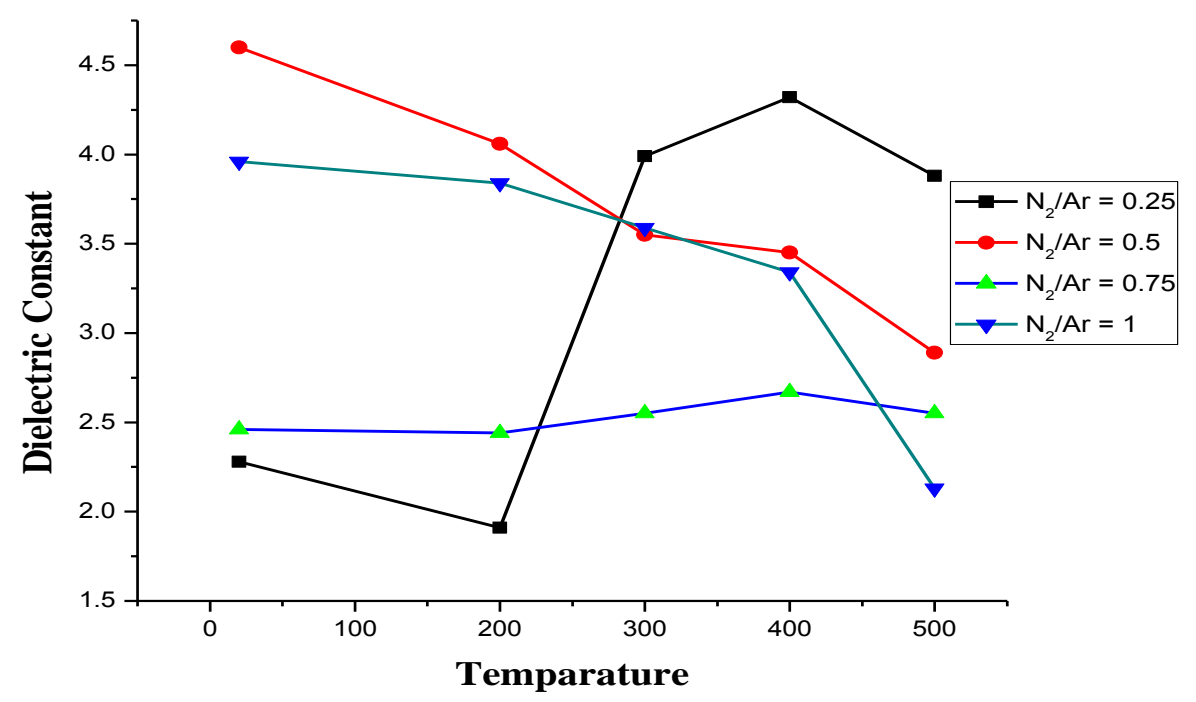

Figure 4.1: Effect of Temperature on Dielectric constant for $2 \mathrm{mtorr}$ pressure 


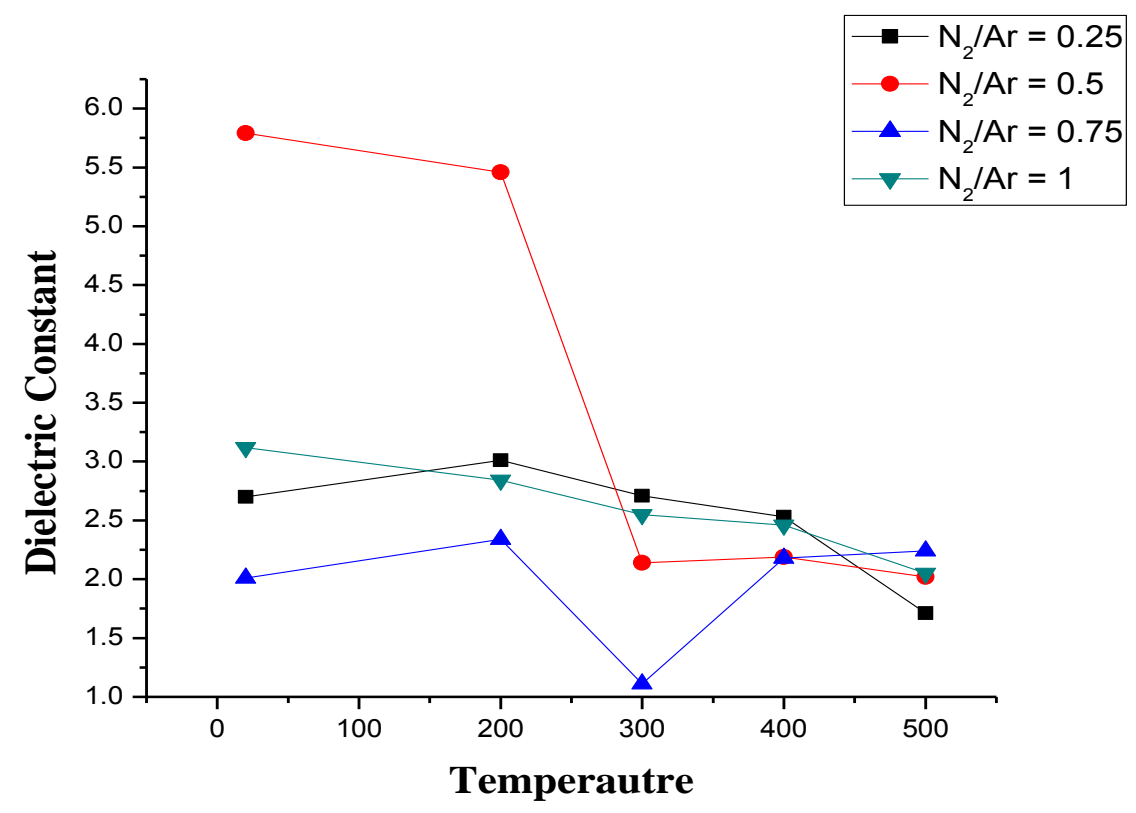

Figure 4.2: Effect of Temperature on Dielectric constant for 5mtorr pressure.

\subsection{2: Dielectric constant v/s Gas flow ratios}

Figure 4.3 shows the plot of Dielectric constant vs $\mathrm{N}_{2} / \mathrm{Ar}$ gas flow ratios at different deposition temperatures and at 2mtorr deposition pressure and Figure 4.4 shows the plot of Dielectric constant vs $\mathrm{N}_{2} / \mathrm{Ar}$ gas flow ratios at different deposition temperatures and at 5mtorr deposition pressure. Both the plots show a decreasing trend of dielectric constant with the $\mathrm{N}_{2} / \mathrm{Ar}$ gas flow ratio initially and an increasing trend at the end. This may be attributed to the fact that the contents of nitrogen and carbon are associated with the dielectric constant variations. More the carbon content and lesser the nitrogen content may bring the characteristics of $\mathrm{B}_{4} \mathrm{C}$. As we know from the literature the dielectric constant of $\mathrm{B}_{4} \mathrm{C}$ is around 4.8 to 8 [24] and the dielectric constant of $\mathrm{BN}$ is around 3.9 to 4.3 [25]. Also the fact that the concentration of nitrogen in the films deposited at $\mathrm{N}_{2} / \mathrm{Ar}=1$ may be lesser because of less sputtering as the amount of argon 
decreases with the domination of nitrogen in the sputtering ambient. Hence the dielectric constant is found to increase towards $\mathrm{N}_{2} / \mathrm{Ar}=1$ flow ratio towards the end.

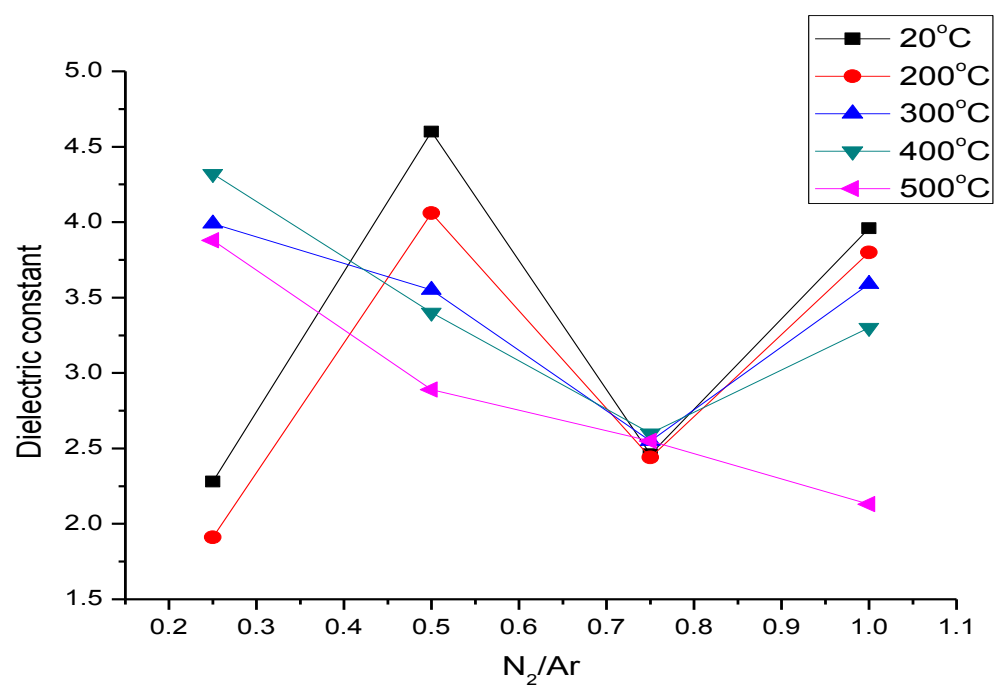

Figure 4.3: Effect of $\mathrm{N}_{2} / \mathrm{Ar}$ flow ratio on Dielectric constant at 2mtorr pressure

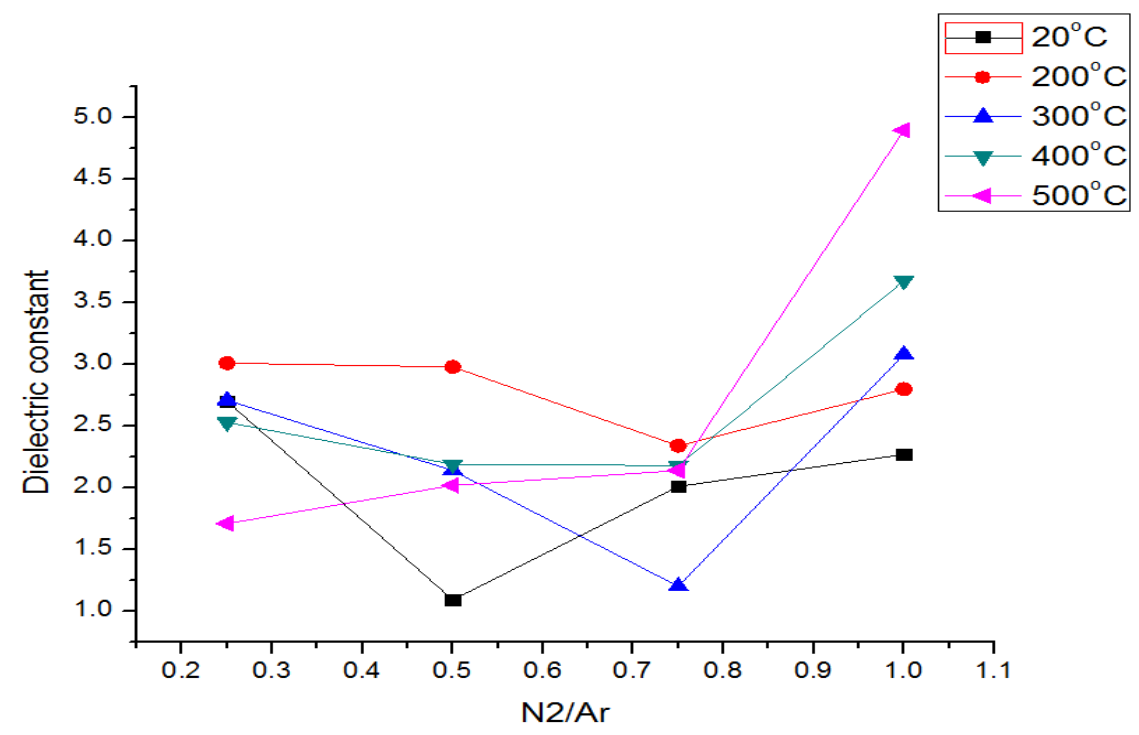

Figure 4.4: Effect of $\mathrm{N}_{2} / \mathrm{Ar}$ gas flow ratio on Dielectric constant at 5mtorr pressure 


\subsection{3: Resistivity vs $\mathrm{N}_{2} / \mathrm{Ar}$ Gas flow ratios}

Figure 4.5 shows the plot of resistivity vs $\mathrm{N}_{2} / \mathrm{Ar}$ gas flow ratios at different deposition temperatures and at 2 mtorr deposition pressure and Figure 4.6 shows the plot of resistivity vs $\mathrm{N}_{2} /$ Ar gas flow ratios at different deposition temperatures and at 5mtorr deposition pressure. As shown in the figure 4.5 for films deposited at 2 mtorr pressure, the resistivity has an increase in trend initially but then tends to stabilize at a constant value towards the higher $\mathrm{N}_{2} / \mathrm{Ar}$ gas flow ratios. When considering the figure 4.6 for films deposited at 5mtorr pressure at different temperatures, resistivity shows an initial decrease in trend at higher temperature and later on it seems to stabilize with less variation with the increase in $\mathrm{N}_{2} / \mathrm{Ar}$ gas flow ratios. From the below two graphs it can be concluded that high resistivity films can be deposited at lower range of temperatures than the higher range. Also at lower temperature range we can obtain high resistivity films for a wide range of $\mathrm{N}_{2} / \mathrm{Ar}$ gas flow ratios at 2 mtorr and 5 mtorr pressure.

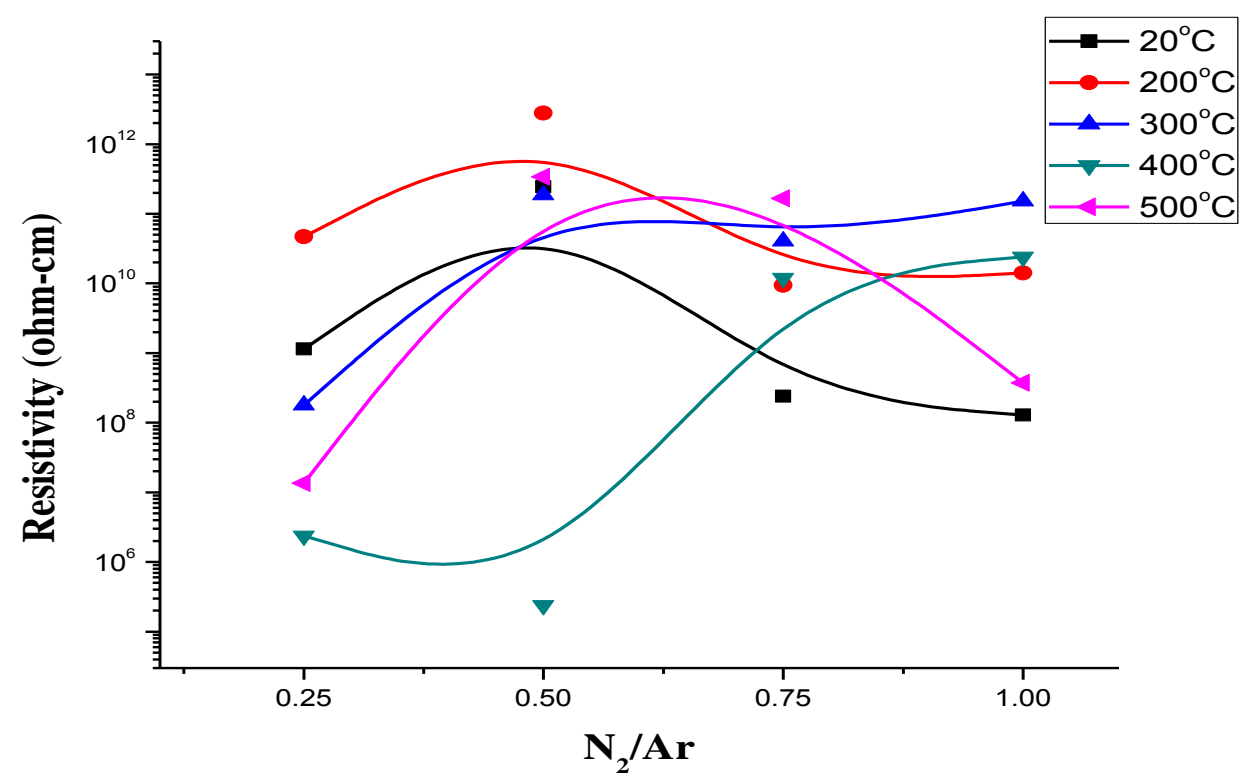

Figure 4.5: Effect of $\mathrm{N}_{2} / \mathrm{Ar}$ gas flow ratio on Resistivity for 2 mtorr pressure 


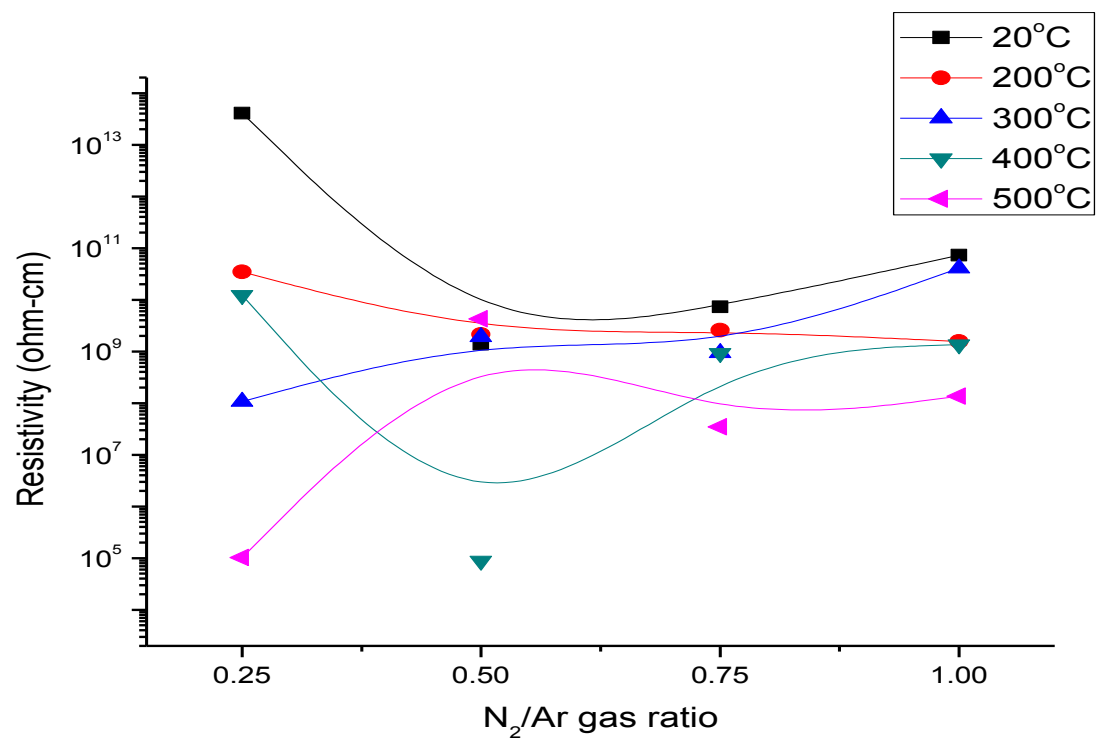

Figure 4.6: Effect of $\mathrm{N}_{2} /$ Ar gas flow ratio on Resistivity for 5mtorr pressure

\subsection{4: Resistivity vs Deposition temperature}

Figure 4.7 shows the plot of resistivity vs deposition temperatures at different $\mathrm{N}_{2} / \mathrm{Ar}$ gas flow ratios 5mtorr deposition pressure and Figure 4.8 shows the plot of resistivity vs deposition temperatures at different $\mathrm{N}_{2} / \mathrm{Ar}$ gas flow at 2 mtorr deposition pressure. The resistivity has a decreasing trend with respect to deposition temperature for 5mtorr deposition pressure and even for the deposition pressure of 2 mtorr the resistivity decreases with respect to increase in deposition temperature. As from the graphs below we can see that the resistivity values maintain a constant value for a wide range of temperatures which shows the robustness of BCN films at wide range of temperature but shows a slight decreasing trend at very high temperatures. This can be due to the aluminum diffusion into the $\mathrm{BCN}$ films at high temperatures thereby causing 
induced polarization and hence bringing down the resistivity considerably.

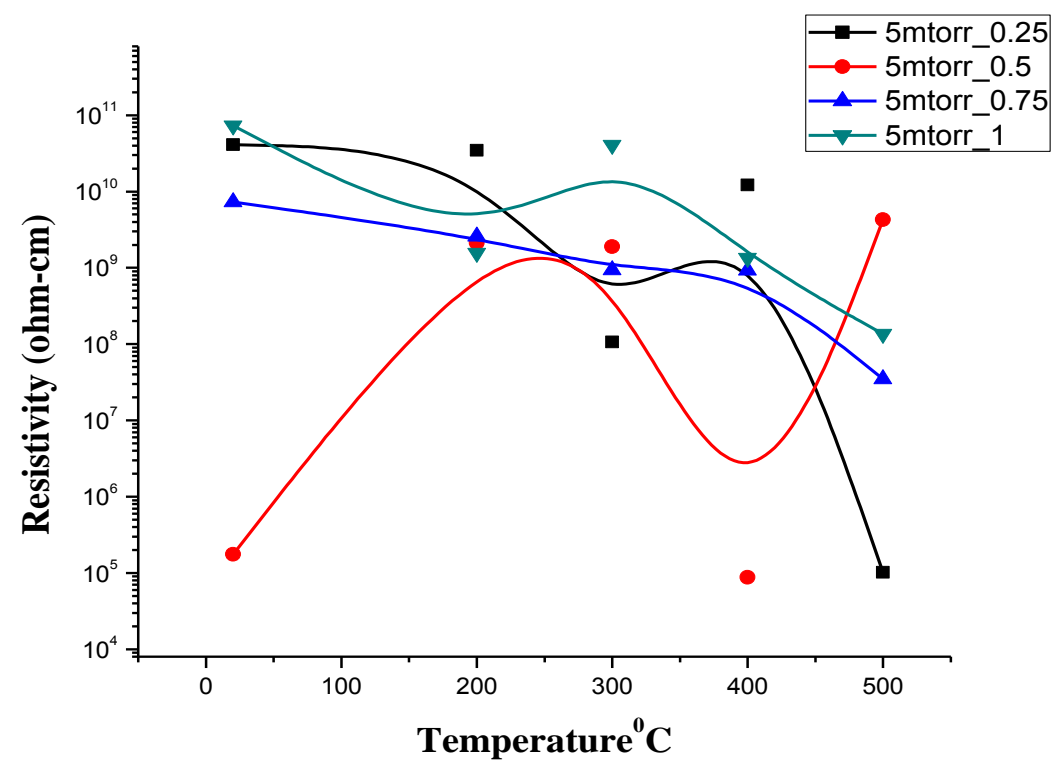

Figure 4.7: Effect of deposition temperature on Resistivity for 5mtorr pressure

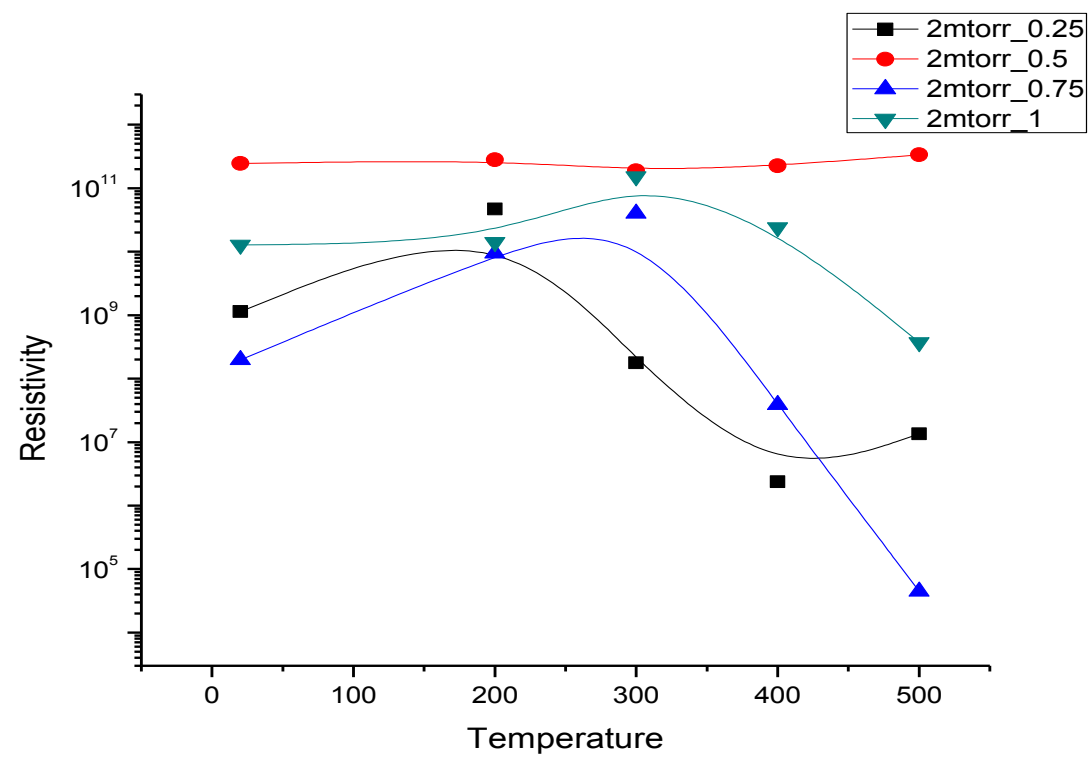

Figure 4.8: Effect of deposition temperature on Resistivity for 2mtorr pressure 


\subsection{5: Breakdown Voltage vs $\mathrm{N}_{2} /$ Ar gas flow ratio}

Figure 4.9 shows the plot of Breakdown Voltage vs $\mathrm{N}_{2} / \mathrm{Ar}$ gas flow ratios at different deposition temperatures and at 2mtorr deposition pressure and Figure 4.10 shows the plot of Breakdown Voltage vs $\mathrm{N}_{2}$ /Ar gas flow ratios at different deposition temperatures and at 5mtorr deposition pressure. As shown in the figure 4.9 for films deposited at 2 mtorr pressure, the Breakdown Voltage has a slight increase in trend with increase in $\mathrm{N}_{2} / \mathrm{Ar}$ ratio but becomes almost stable in the end. When considering the figure 4.10 for films deposited at 5mtorr pressure at different temperatures, breakdown voltage shows a stabilizing trend with the slight increase in $\mathrm{N}_{2} / \mathrm{Ar}$ gas flow ratios from $\mathrm{N}_{2} / \mathrm{Ar}=0.25$ to 0.75 , but has a kind of decreasing trend at the end. This property of maintaining constant breakdown voltage over a range of gas ratios shows that devices can be fabricated with BCN as ILD at different range of gas flow ratios depending upon the feasibility of fabrication. The decrease in breakdown voltage at $\mathrm{N}_{2} / \mathrm{Ar}=1$ may be due to the lesser concentration of nitrogen at that ratio and hence more the characteristic of $\mathrm{B}_{4} \mathrm{C}$ (which has lower resistivity than $\mathrm{BN}$ ). 


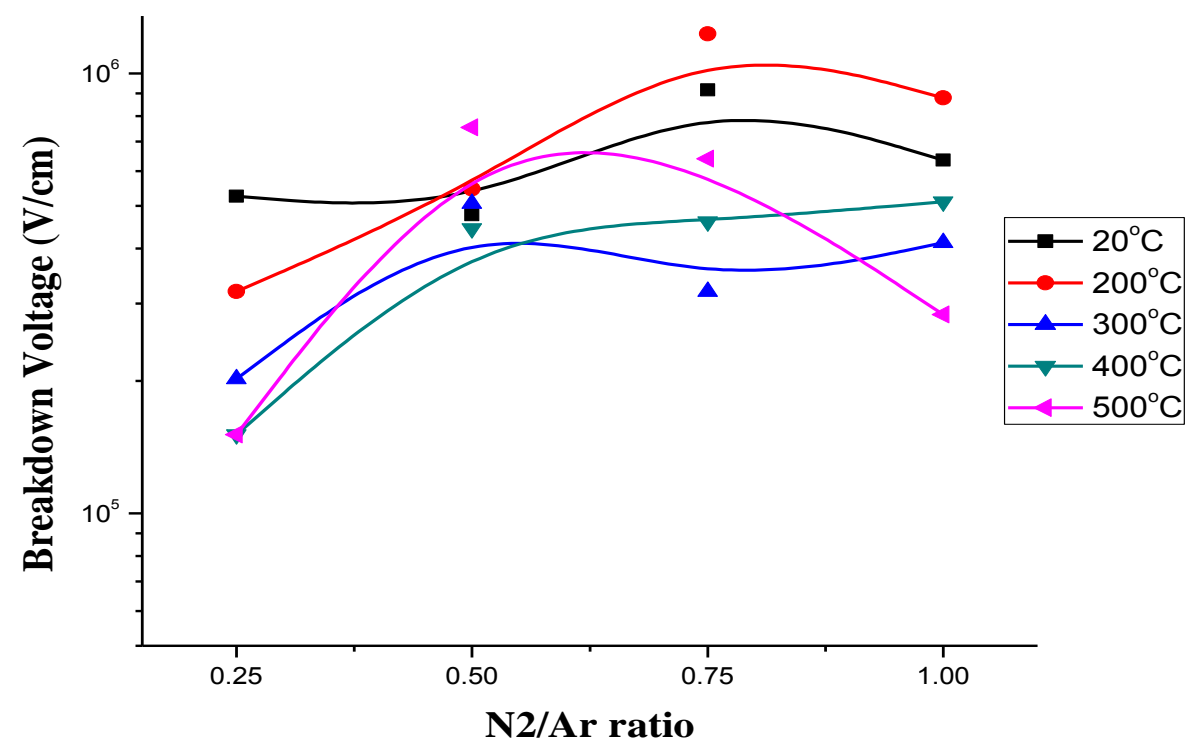

Figure 4.9: Effect of $\mathrm{N}_{2} / \mathrm{Ar}$ gas flow ratio on Breakdown voltage at $2 \mathrm{mtorr}$ pressure

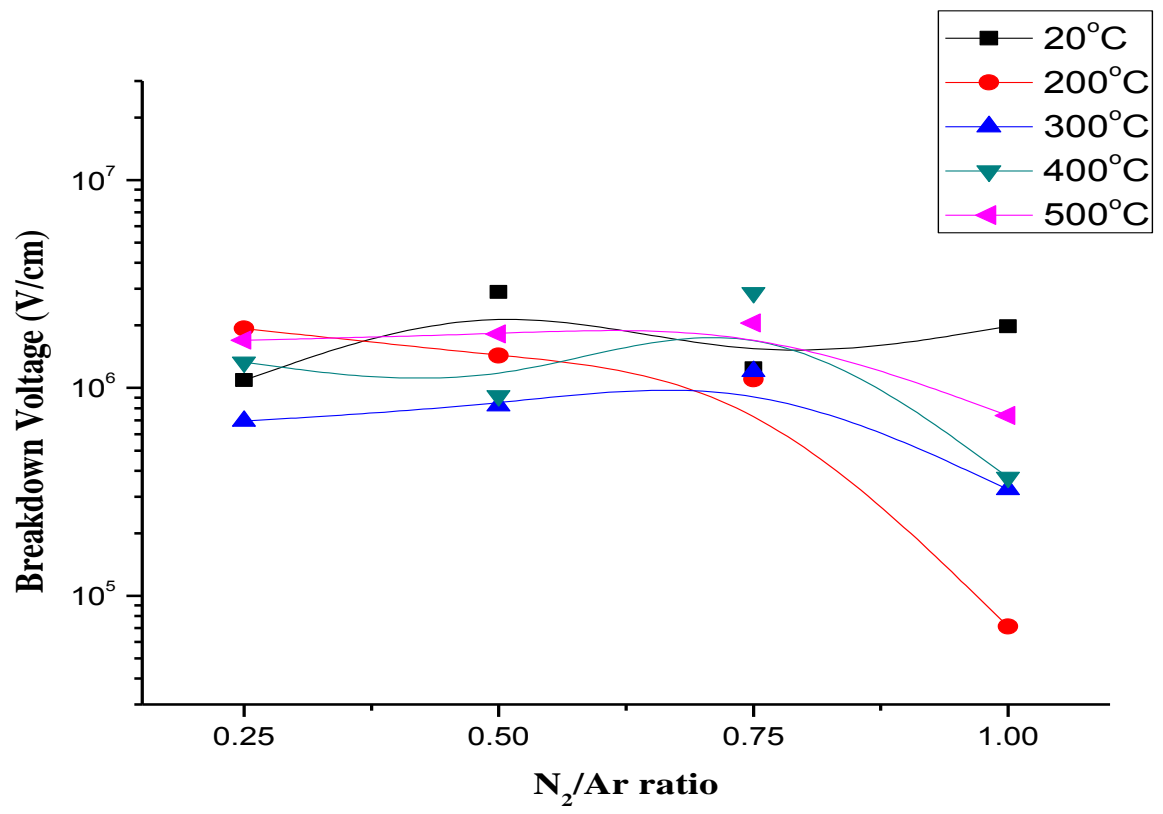

Figure 4.10: Effect of $\mathrm{N}_{2} / \mathrm{Ar}$ gas flow ratio on Breakdown voltage at 5mtorr pressure 


\subsection{6: Breakdown Voltage vs. Temperature}

Figure 4.11 shows the plot of Breakdown Voltage vs. Deposition temperatures at different $\mathrm{N}_{2} / \mathrm{Ar}$ gas flow ratios and at 2mtorr deposition pressure and Figure 4.12 shows the plot of Breakdown Voltage vs. Deposition temperatures at different $\mathrm{N}_{2} / \mathrm{Ar}$ gas flow ratios and at 5mtorr deposition pressure. As shown in the figure 4.11 for films deposited at $2 \mathrm{mtorr}$ pressure, the Breakdown Voltage has an increase in trend with increase in temperature initially but has a kind of decreasing trend overall. When considering the figure 4.12 for films deposited at $5 \mathrm{mtorr}$ pressure at different temperatures, breakdown voltage shows an initial increase in trend and later on it shows a decreasing trend with the increase in temperature but has a kind of Increase in trend in the end. Comparing both the graphs it can be concluded that for a range of deposition temperatures the breakdown voltage of the $\mathrm{BCN}$ film deposited at 5mtorr showed more robustness than that of 2 mtorr ones as the value of resistivity didn't fall much below the order of $5 \times 10^{5} \mathrm{~V} / \mathrm{cm}$. 


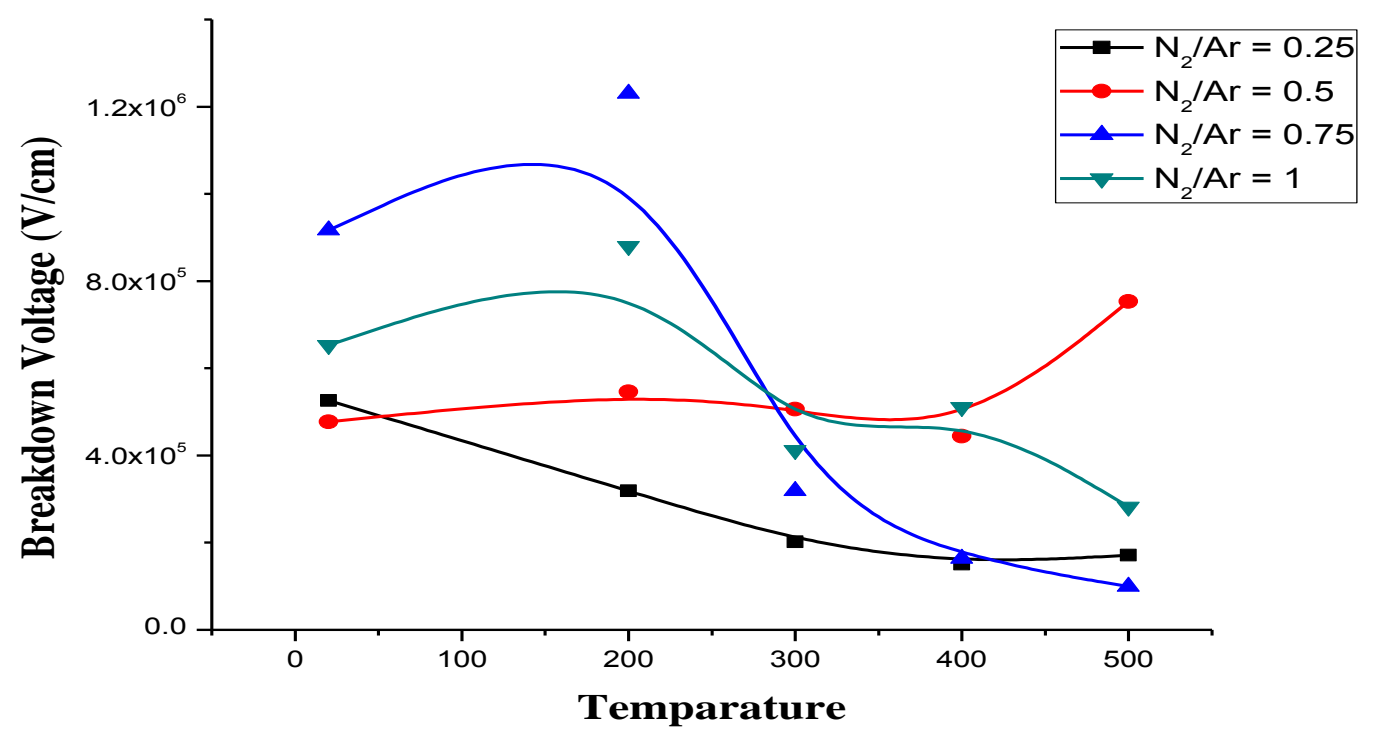

Figure 4.11: Effect of Temperature on Breakdown voltage at 2mtorr pressure

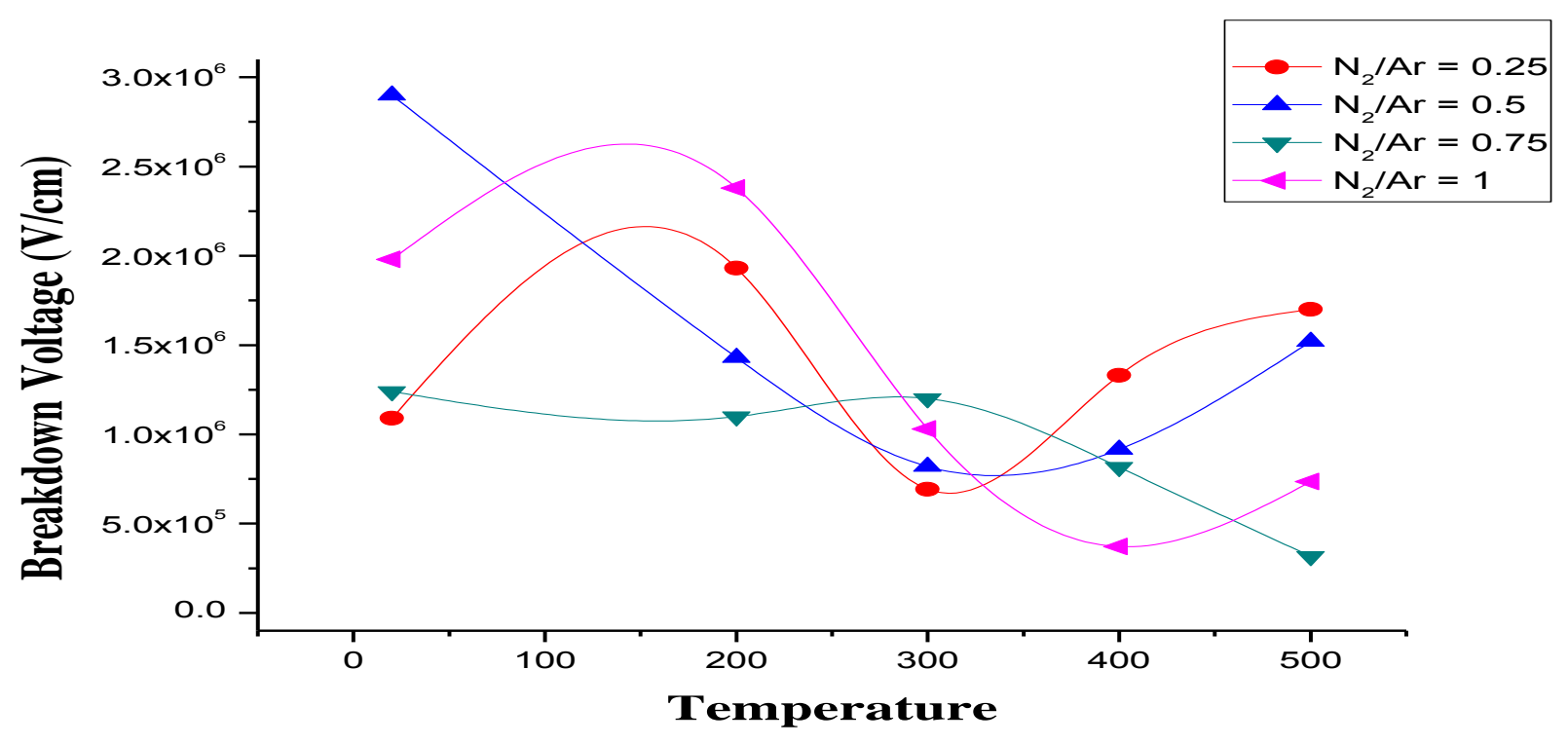

Figure 4.12: Effect of Temperature on Breakdown voltage at 5mtorr pressure 


\section{CHAPTER 5: CONCLUSION}

BCN thin films were deposited successfully by RF magnetron sputtering from $\mathrm{B}_{4} \mathrm{C}$ target in argon and nitrogen gas ambient. Electrical characteristics are strongly dependent on the $\mathrm{N}_{2} / \mathrm{Ar}$ flow ratio during deposition and various other parameters like deposition temperatures, RF power, and deposition pressures. The electrical properties BCN thin films have been investigated to see it as a possible material having a low dielectric constant to be used as a interlayer dielectric (ILD) in the VLSI and ULSI. The Current-Voltage (I-V) plots were attained for the AlBCN-Al (MIM) structures. By using the I-V characteristics the Breakdown voltage was found out as well as resistivity. Dielectric constant of the BCN films was also calculated from capacitance across the MIM structures. This work has been conducted to forge a relationship between various electrical parameters as a function of various deposition temperatures and $\mathrm{N}_{2} / \mathrm{Ar}$ gas flow ratios under different deposition pressures. The dielectric constant decreases with increase in nitrogen in the $\mathrm{BCN}$ film and also with the increase in substrate temperature as it shows more BN kind of characteristics. The Breakdown voltage increases with $\mathrm{N}_{2}$ and also with the substrate temperature it increases initially but shows a slight decreasing trend thereafter. The resistivity of the film is found to be almost constant and tend to vary very little with increase in substrate temperature and this shows its wide range of operability in different conditions of temperature, gas ratios and deposition pressures. BCN can thus be chosen for IDL as a trade of between the high resistivity, high breakdown voltage, higher dielectric constant of Boron Nitride and low dielectric constant, lower resistivity, and lower breakdown voltage of Boron nitride. 


\section{FUTURE WORK}

Dual target reactive magnetron sputtering can be used to produce $\mathrm{BCN}$ thin films from $\mathrm{B}_{4} \mathrm{C}$ and $\mathrm{BN}$ targets and related optical, electrical and mechanical characterization can be studied and its feasibility as a new low-k dielectric material which could replace the existing low-k Inter dielectric layer (IDL) will be determined. Also many of its other applications related to hardness and wear resistance can be studied. BCN as a possible optical sensor can be fabricated, as it has potential for many optical applications 


\section{LIST OF REFERENCES}

[1] Interlayer dielectric for semiconductor technology edited by S.P Murarka, M. Eizenberg, A. k Sinha

[2] Bohr, M. (1995). Tech. Digest IEEE Int. Electronic Device Meeting, p.241.

[3] D.C. Reigada, F.L. Freire, Diamond and related materials 16 (2007) 1441.

[4] M, Kawaguchi, Advanced Materials, vol. 9, 1997, pp. 615.

[5] S.Umeda, T.Yuki, T. Sugiyama and T. Sugino, "Boron carbon nitride film with low dielectric constant as passivation film for high speed electronic devices", Diamond and related materials, 13 (4-8), (2004) 1135.

[6] M.O.Watanabe, S.Itoh, K.Mizushima, T.Sasaki, Applied Physics Letters, 68 (21), (1996), pp. 2962.

[7] "Rutgers working on body armor". Asbury Park Press. August 11, 2012. Retrieved 2012-0812. "Boron carbide is the third-hardest material on earth."

[8] Conde, O., Silvestre, A.J., Oliveira, J.C., "Influence of carbon content on the crystallographic structure of boron carbide films", Surface Coatings Technology, 125, (2000), pp. 141.

[9] Boron Carbide: Structure, Properties, and Stability under Stress Vladislav Domnich, Sara Reynaud, Richard A. Haber, and Manish Chhowalla, Department of Materials Science and Engineering, Rutgers, The State University of New Jersey.

[10] Pierson, H.O. 1996: Handbook of Refractory Carbides and Nitrides, pp. 118- 154, Noyes Publications, New Jersey, USA.

[11] Lee, S., Mazurowski, J., Ramseyer, G., Dowben, P.A., 1992: Characterization of boron carbide thin films fabricated by plasma enhanced chemical vapor deposition from boranes, 
Journal of Applied Physics, Vol. 72, no. 10, (1992), pp. 4925.

[12] Ahmad, A.A., Ianno, N.J., Hwang, S.D., Dowben, P.A., "Sputter deposition of high resistivity boron carbide”, Thin Solid Films, vol. 335, no. 1-2, (1998), pp. 174.

[13] Sunwoo Lee, Syracuse University, Syracuse, New York, John Mazurowski, Syracuse University, Syracuse, NY, G. Ramseyer, General Electric Company, Peter A. Dowben, University of Nebraska-Lincoln, "Characterization of boron carbide thin films fabricated by plasma enhanced chemical vapor deposition from boranes".

[14] Mishima M, Tanaka J, Yamaoka S, Furunaga O., Science, 238, (1987), pp. 181

[15]R.F. Davis (1991). "III-V Nitrides for Electronic and Optoelectronic applications". Proceedings of the IEEE 79 (5): 702-712.

[16] Thévenot, F., "Boron carbide-A comprehensive review", Journal of the European Ceramic Society, 6, (1990), pp. 205.

[17] Sezer, A.O., Brand, J.I., "Chemical vapor deposition of boron carbide”, Materials Science and Engineering B, 79, (2001), pp. 191.

[18] M.O. Watanabe, S. Itoh, K. Mizushima, "Electrical properties of BC2N thin films prepared by chemical vapor deposition," Journal of Applied Physics, 78, (1995), pp. 2880.

[19] J.Yue, W.Chang, X. Zhng, D.He nd G.Chen, "Ternary BCN thin films deposited by reactive sputtering”, Thin Solid Films, 375 (2000), pp. 247-250.

[20] Liu L., Wang Y., Feng K., Li Y, Li W, Zhao C., Zhao Y., "Preparation of boron carbon nitride thin films by radio frequency magnetron sputtering", Applied Surface Science, 252, (2006), pp. 4185-4189.

[21] E. Martinez, A. Lousa and J. Esteve "Micromechanical and microtribological properties of 
$\mathrm{B}_{4} \mathrm{C}$ thin films near the $\mathrm{B}_{4} \mathrm{C}$ composition deposited by r.f magnetron sputtering", Diamond and related materials, 10 (2001), pp. 1892-1896.

[22] Takashi Sugino, Yoshihiro Etou, and Tomoyoshi Tai "Dielectric constant of boron carbon nitride films synthesized by plasma-assisted chemical-vapor deposition", Applied Physics Letters, 80, (2002), pp. 649-651.

[23] T. Sugino and T. Tai, Jpn. J. Appl. Phys., Part 2 39, L1101 (2000).

[24] "Boron Carbide $\left(\mathrm{B}_{4} \mathrm{C}\right)$ Properties and Information about Boron Carbide", http://www.azom.com/properties.aspx?ArticleID=75.

[25]"Boron Nitride (BN) - Properties and Information on Boron Nitride" http://www.azom.com/properties.aspx?ArticleID=78

[26] A.Y. Liu, M.L. Cohen, "Carbon nitride and other speculative superhard materials", Science, 245, (1989), pp. 841-842

[27] Kouvetakis J, Bhandari A, Todd M, Wilkens B and Cave N, Chem. Mater., 6, (1994), pp. 811.

[28] Nakayama N, Tsuchiya Y, Tamada S, Kosuge K, Nagata S, Takahiro K and Yamaguchi S, Japanese Journal of Applied Physics, 32, (1993), pp. L1465.

[29] Fowler, R.H. and Nordheim, L. (1928). Proc. R. Soc. (London), 119, 173

[30] Frenkel, J. (1938). Phys. Rev. 54, 647.

[31] Wu, X.M., Soss, S.R., Rymaszewski, E.J., and Lu, T.M. (1994). Mater. Chem. Phys. 38, 297.

[32] Lerner, R. G. and Triggs, G.L., Eds. (1981). Encyclopedia of Physics, Addison-Wesley Reading, MA, p. 769 
[33] Harrop, P.J and Campbell, D.S. (1970). In Handbook of thin film Technology, (Eds. L.I. Maissel and R. Glang). McGraw-Hill, New York, pp. 16-17.

[34] W.J.Pan et al., Applied Surface Science, 218, pp. 297, (2003) 